\title{
A cell-penetrating ARF peptide inhibitor of FoxM1 in mouse hepatocellular carcinoma treatment
}

\author{
Galina A. Gusarova, ${ }^{1}$ I-Ching Wang, ${ }^{1}$ Michael L. Major, ${ }^{1}$ Vladimir V. Kalinichenko, ${ }^{2}$ \\ Timothy Ackerson, ${ }^{1}$ Vladimir Petrovic, ${ }^{1}$ and Robert H. Costa ${ }^{1}$ \\ ${ }^{1}$ Department of Biochemistry and Molecular Genetics, University of Illinois at Chicago, College of Medicine, Chicago, Illinois, USA. \\ 2Department of Medicine, Pritzker School of Medicine, The University of Chicago, Chicago, Illinois, USA.
}

\begin{abstract}
The forkbead box m1 (Foxm1) transcription factor is essential for initiation of carcinogen-induced liver tumors; however, whether FoxM1 constitutes a therapeutic target for liver cancer treatment remains unknown. In this study, we used diethylnitrosamine/phenobarbital treatment to induce hepatocellular carcinomas (HCCs) in either WT mice or Arf $/-$ Rosa26-FoxM1b Tg mice, in which forkhead box M1b (FoxM1b) is overexpressed and alternative reading frame (ARF) inhibition of FoxM1 transcriptional activity is eliminated. To pharmacologically reduce FoxM1 activity in HCCs, we subjected these HCC-bearing mice to daily injections of a cell-penetrating $\mathrm{ARF}_{26-44}$ peptide inhibitor of FoxM1 function. After 4 weeks of this treatment, HCC regions displayed reduced tumor cell proliferation and angiogenesis and a significant increase in apoptosis within the HCC region but not in the adjacent normal liver tissue. ARF peptide treatment also induced apoptosis of several distinct human hepatoma cell lines, which correlated with reduced protein levels of the mitotic regulatory genes encoding polo-like kinase 1 , aurora $B$ kinase, and survivin, all of which are transcriptional targets of FoxM1 that are highly expressed in cancer cells and function to prevent apoptosis. These studies indicate that ARF peptide treatment is an effective therapeutic approach to limit proliferation and induce apoptosis of liver cancer cells in vivo.
\end{abstract}

\section{Introduction}

Human hepatocellular carcinoma (HCC) is the fifth most common cancer, yet it is among the most lethal cancers worldwide because late detection and high frequency of tumor recurrence render current HCC therapy ineffective (1). The primary etiology of human HCC involves HBV and HCV infections, which are primarily responsible for the high incidence of HCC in Africa and Asia and increasing occurrence of HCC in Europe and America (1). Persistent hepatic infection by either human HBV or HCV results in chronic hepatic inflammatory injury and activation of hepatic stellate cells, which oversecrete collagen, leading to hepatic fibrosis, cirrhosis, and subsequent development of HCC (1). Other causes of human HCC involve hepatic damage and fibrosis resulting from iron or copper deposition, alcohol, or nonalcoholic steatohepatitis (NASH, or fatty liver disease) as well as exposure to the potent hepatic carcinogen aflatoxin B1 produced by specific strains of mold (1).

Activation of the Ras/MAPK signaling pathway drives cellcycle progression by temporal expression of cyclin regulatory subunits, which activate their corresponding cyclin-dependent kinases (CDKs) through complex formation and phosphorylate substrates critical for cell-cycle progression (2). Development of cancer is a multistep process involving gain-of-function

Nonstandard abbreviations used: ARF, alternative reading frame; $\mathrm{CDK}$, cyclindependent kinase; CDKI, CDK inhibitor; $\mathrm{CKO}$, conditional(ly) KO; D-Arg, D-arginine; DEN, diethylnitrosamine; dsRNA, double-stranded RNA; Fox, forkhead box; HCC, hepatocellular carcinoma; HMEC-1 cell, human microvascular endothelial cell; PB, phenobarbital; PLK1, polo-like kinase 1; PUMA, p53-upregulated modifier of apoptosis; TMR, tetramethylrhodamine.

Conflict of interest: The authors have declared that no conflict of interest exists. Citation for this article: J. Clin. Invest. 117:99-111 (2007). doi:10.1172/JCI27527. mutations that activate the Ras/MAPK and PI3K/Akt signaling pathways that stimulate cell-cycle progression and enhance cell survival $(2,3)$. Cancer progression also requires inactivation of tumor suppressor genes that function to arrest cell proliferation in response to oncogenic stimuli (4). In mouse models of liver cancer, loss-of-function mutations in the p53 tumor suppressor gene or gain-of-function mutations in either the Ras/MAPK, $\mathrm{PI} 3 \mathrm{~K} / \mathrm{Akt}$, or TGF- $\alpha$ signaling pathways are known to stimulate formation of HCC tumors (5-7). A well-established mouse liver tumor induction and promotion protocol is available and consists of a single postnatal injection of the DNA-damaging diethylnitrosamine (DEN; tumor initiator) and continuous administration of the tumor promoter phenobarbital (PB) (8). Gene expression profiling studies demonstrated that mouse HCCs induced by DEN treatment express genes similar to those found in the poorer survival group of human HCCs (9), supporting the relevance of using DEN-induced mouse liver tumors as a model for the study of human liver tumors.

Expression of the alternative reading frame (ARF) tumor suppressor protein is induced in response to oncogenic stimuli and prevents abnormal cell proliferation through a $\mathrm{p} 53$-dependent $\mathrm{G}_{1}$ cell-cycle arrest by increasing stability of the p53 tumor suppressor through nucleolar targeting of the p53 ubiquitin ligase protein Mdm2 (10). The ARF protein also mediates p53-independent cell-cycle arrest, as the mouse ARF protein targets both the E2F1 and c-Myc transcription factors to the nucleolus, thus preventing their transcriptional activation of S-phase-promoting target genes (11-14). Loss of ARF function is a critical event for tumor promotion, as evidenced by extinguished expression of the ARF protein in a variety of tumors through DNA methylation and silencing of the ARF promoter region (4). 
A DEN
$14 \mathrm{~d}$ PN
Mx-Cre Foxm $1^{\text {Int }}$
and Foxm $1^{\text {HII }}$ mice
dsRNA-induced $M x$-Cre

deletion of Foxm $1^{|(\mid)|}$

allele in liver tumors
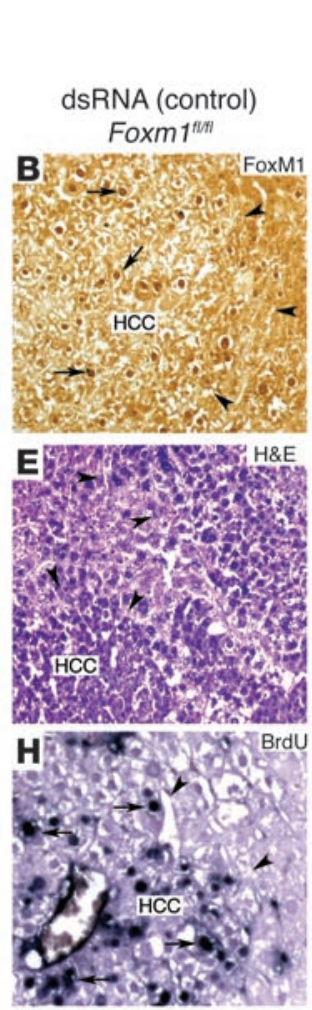

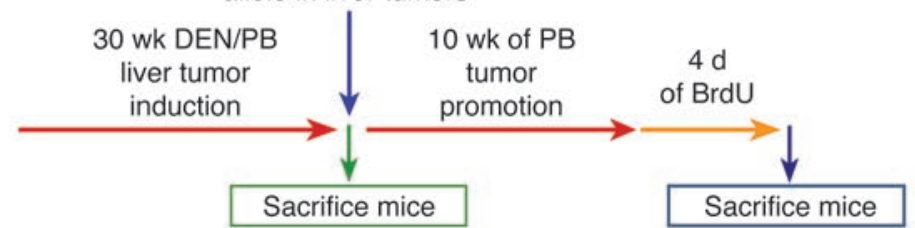

Sacrifice mice

Sacrifice mice

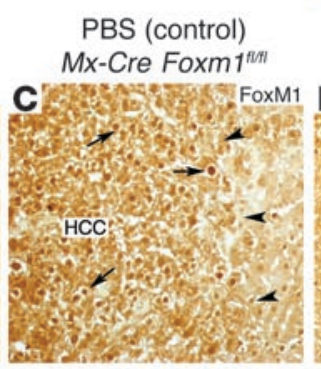

dsRNA (CKO)

Mx-Cre Foxm 1-1-
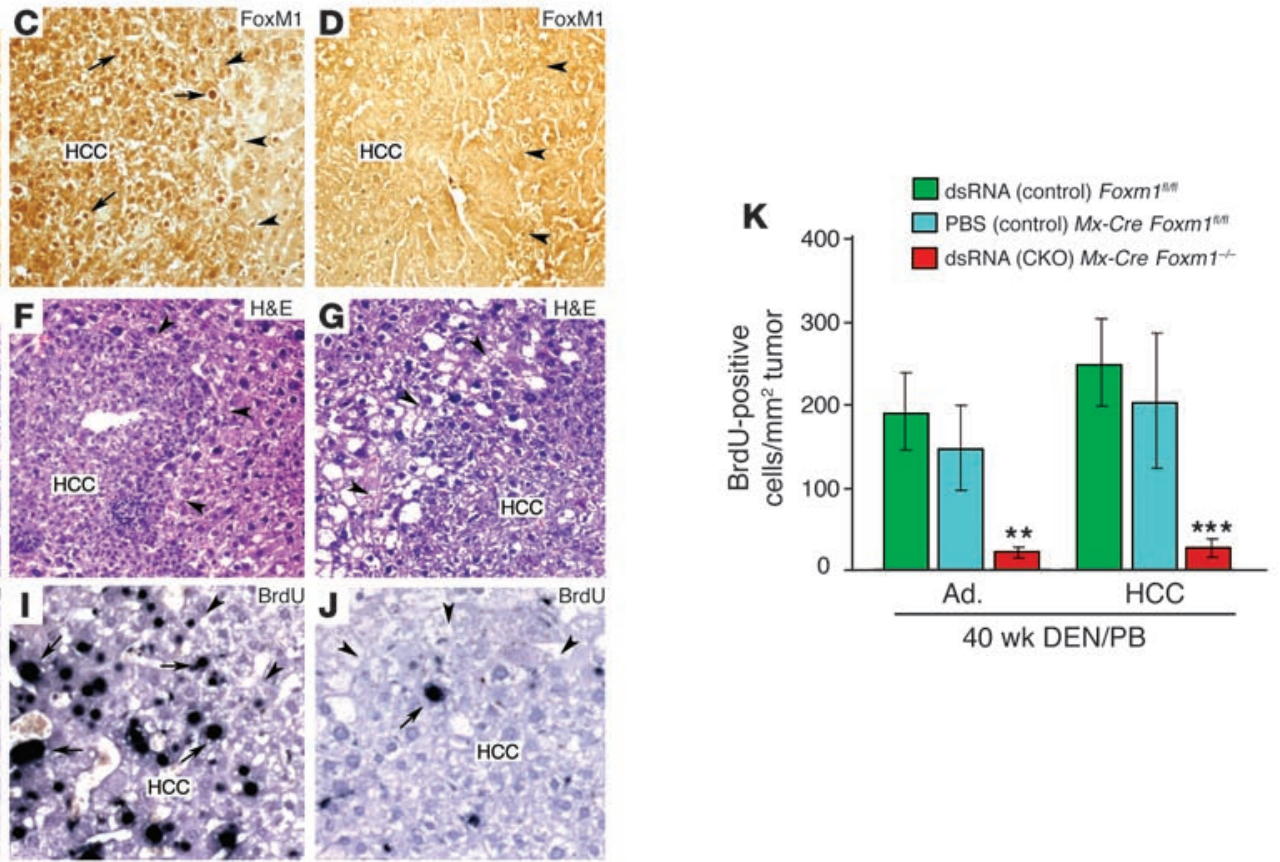

\section{Figure 1}

The mouse Foxm1 transcription factor is required for hepatic tumor progression. (A) Diagram depicting experimental design of conditional deletion of Foxm $1^{\text {fl/fl }}$ in preexisting liver tumors. See Methods for details of DEN/PB treatment of mice to induce HCCs as described previously (8). To create the Foxm1 CKO, mice were injected with synthetic dsRNA to induce expression of the $M x$-Cre recombinase transgene (Mx-Cre) to delete the mouse Foxm $1^{f / f l}$ targeted allele at 30 weeks after DEN/PB treatment, and the mice were then subjected to 10 additional weeks of PB tumor promotion and were labeled with BrdU as described in Methods. Controls included dsRNA-treated Foxm $1^{f / f t}$ mice and PBS-treated $M x$-Cre Foxm $1^{f \mid / t l}$ mice. PN, postnatally. (B-D) dsRNA CKO Mx-Cre Foxm1-- liver tumors display no detectable nuclear staining of Foxm1 protein as determined by immunostaining with Foxm1 antibody. (E-G) H\&E staining of the indicated HCC liver sections after 40 weeks of DEN/PB exposure (tumor margins indicated by arrowheads). (H-J) BrdU incorporation was detected by immunostaining of liver tumor sections with monoclonal BrdU antibody from the indicated mice at 40 weeks following DEN/PB exposure. Arrows indicate nuclear staining for either Foxm1 protein or BrdU. (K) Graph of mean number of BrdU-positive cells per square millimeter liver tumor $( \pm \mathrm{SD})$ as described in Methods. The asterisks indicate statistically significant changes: ${ }^{* *} P \leq 0.01$ and ${ }^{* *} P \leq 0.001$. Ad., hepatic adenomas. Magnification: $\times 200(\mathbf{B}-\mathbf{G}) ; \times 400(\mathbf{H}-\mathbf{J})$.

The mammalian forkhead box (Fox) family of transcription factors consists of more than 50 mammalian proteins $(15,16)$ that share homology in the winged helix DNA-binding domain $(17,18)$. Expression of FoxM1 (or FoxM1b) is ubiquitous in all proliferating mammalian cells, and its expression is induced during the $G_{1}$ phase of the cell cycle and continues during S-phase and mitosis (19-23). FoxM1b transcriptional activity requires activation of the RAS/MAPK pathway and binding of activated CDK-cyclin complexes to the activation domain, which mediate phosphorylation-dependent recruitment of the CREB-binding protein (CBP) transcriptional coactivator (24). Liver regeneration studies that used the albumin promoter/enhancer cre recombinase ( $\mathrm{Alb}$-Cre) transgene to mediate hepatocyte-specific deletion of the mouse Foxm1 LoxP/LoxP targeted allele (Foxm $1^{f / f l}$ ) demonstrated that Foxm1 is required for hepatocyte DNA replication and mitosis (25). Foxm1-deficient hepatocytes accumulate nuclear levels of the CDK inhibitor (CDKI) proteins $\mathrm{p} 21^{\mathrm{Cip} 1}$ and $\mathrm{p} 27^{\mathrm{Kip} 1}$ $(8,25)$ because FoxM1 regulates expression of S-phase kinase-associated protein 2 (Skp2) and CDK subunit 1 (Cks1) proteins (26), which are involved in targeting these CDKI proteins for degradation during the $\mathrm{G}_{1} / \mathrm{S}$ transition (27). For $\mathrm{G}_{2} / \mathrm{M}$ progression, FoxM1 regulates transcription of cyclin $\mathrm{B} 1$ and the $\mathrm{Cdk} 1$-activating $\mathrm{Cdc} 25 \mathrm{~B}$ phosphatase $(25,28)$, and FoxM1 is essential for transcription of the mitotic regulatory genes polo-like kinase 1 (PLK1), aurora B kinase, survivin, centromere protein A (CENPA), and CENPB $(26,29,30)$.

We previously used the Alb-Cre transgene to conditionally delete the mouse Foxm $1^{f / f l}$ allele in hepatocytes prior to DEN/PB liver 


\title{
Table 1
}

WT ARF peptide treatment diminishes the number and size of hepatic adenomas and HCCs per square centimeter liver tissue

\section{Foxm1 mouse genotype or ARF peptide treatment $(40 \text { weeks } \mathrm{DEN} / \mathrm{PB})^{\mathrm{A}}$ \\ No. mice ${ }^{B}$}

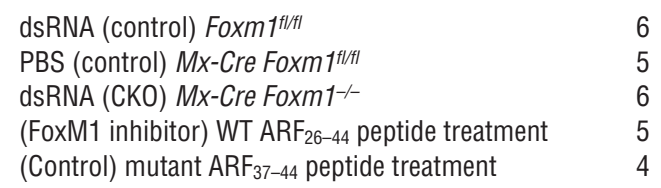

\begin{tabular}{llc} 
mice $^{B}$ & \multicolumn{3}{l}{ No. liver tumors between } \\
& $\mathbf{0 . 1}$ and $\mathbf{2 . 0} \mathbf{m m}^{2}$ in size \\
& No. Ad. & No. HCCs \\
6 & $2.8 \pm 1.8$ & $7.1 \pm 4.0$ \\
5 & $1.3 \pm 0.7$ & $9.2 \pm 4.6$ \\
6 & $2.2 \pm 1.7$ & $3.0 \pm 1.1^{\mathrm{E}}$ \\
5 & $1.6 \pm 0.6 \mathrm{E}$ & $3.0 \pm 2.1 \mathrm{~F}$ \\
4 & $4.9 \pm 1.5$ & $11.7 \pm 2.7$
\end{tabular}
No. liver tumors greater than $2.0 \mathrm{~mm}^{2}$ in size ${ }^{\mathrm{D}}$
No. Ad.
$2.6 \pm 1.3$
$3.9 \pm 1.5$
$2.1 \pm 0.8 \mathrm{~F}$
$4.5 \pm 0.9$
$0.22 \pm 0.4 \mathrm{E}$

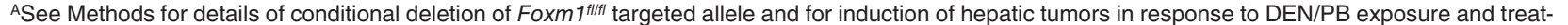
ment with WT ARF $26-44$ peptide or mutant $\mathrm{ARF}_{37-44}$ peptide. BNo. mice: number of male mice analyzed for liver tumors after 40 weeks of DEN/PB exposure. $\mathrm{C}, \mathrm{DW}$ We determined the number of liver tumors per square centimeter liver tissue $( \pm \mathrm{SD})$ from H\&E-stained liver sections obtained from 4 different mouse liver lobes. Hepatic adenomas (Ad.) or HCCs found in mouse livers between $0.1 \mathrm{~mm}^{2}$ and $2 \mathrm{~mm}^{2}$ in size (C) or greater than $2 \mathrm{~mm}^{2}$ in size (D). Statistically significant changes: ${ }^{E} P \leq 0.05 ;{ }^{F} P \leq 0.01$. We compared tumor size of $W_{T} A^{A R F} F_{26-44}$ peptide-treated versus mutant $A R F_{37-44}$ peptide-treated liver tumors. We also compared liver tumor size in dsRNA CKO Mx-Cre Foxm1-1- and control mice.
\end{abstract}

tumor induction. FoxM1-deficient hepatocytes failed to proliferate and were resistant to the development of hepatic tumors $(8,31)$. This tumor resistance was associated with increased nuclear levels of the CDKI protein $\mathrm{p} 27^{\mathrm{Kip} 1}$ and undetectable levels of the CDK1 activator Cdc25B phosphatase $(8,31)$. The FoxM1 transcription factor was identified as a novel inhibitory target of the mouse ARF tumor suppressor, and structure-function studies demonstrated that amino acid residues $26-46$ of the mouse ARF protein were sufficient to inhibit FoxM1 (8). Furthermore, treatment of osteosarcoma U2OS cells with a cell-penetrating $\mathrm{ARF}_{26-44}$ peptide containing $9 \mathrm{~N}$-terminal D-arginine (D-Arg) residues (WT ARF $\left.{ }_{26-44}\right)(32,33)$ significantly reduced FoxM1 function in this cancer cell line (8). Moreover, we previously developed $\mathrm{Tg}$ mice in which the Rosa26 promoter was used to drive ubiquitous expression of the human FoxM1b cDNA, and increased FoxM1b levels stimulated proliferation of pulmonary cells in response to lung injury (34) and stimulated development and progression of prostate cancers in both TRAMP/Rosa26-FoxM1b and $L A D Y / R o s a 26-F o x M 1 b$ double-Tg mice (35).

In this study, we used the $M x$ promoter-driven Cre recombinase (Mx-Cre) transgene (36) to conditionally delete the Foxm $1^{f l / f l}$ allele in preexisting mouse liver tumors induced by DEN/PB treatment and demonstrated that FoxM1 is required for tumor progression of hepatic cancer cells. We show that administering the $\mathrm{WT} \mathrm{ARF}_{26-44}$ peptide to mice following DEN/PB exposure is an effective treatment to diminish Foxm1 function in vivo, causing selective HCC apoptosis and reduced proliferation and angiogenesis in HCC regions. We also show that $A r f^{/-}$Rosa26-FoxM1b Tg mice, in which FoxM1b is overexpressed and ARF inhibition of FoxM1 transcriptional activity is eliminated, developed highly proliferative liver tumors following $\mathrm{DEN} / \mathrm{PB}$ exposure. We showed that $\mathrm{WT} \mathrm{ARF}_{26-44}$ peptide treatment of these Arf ${ }^{-}$- Rosa26-FoxM1b Tg mice efficiently diminished HCC proliferation and selectively induced apoptosis of the HCC region.

\section{Results}

The mouse Foxm1 transcription factor is required for hepatic tumor progression. We previously showed that conditional deletion of Foxm1 in hepatocytes prior to DEN/PB liver tumor induction is sufficient to inhibit hepatic tumor initiation $(8,31)$. Here, we determined that Foxm 1 is required for hepatic tumor progression. In order to do so, we used the IFN- $\alpha / \beta$-regulated $M x$-Cre transgene (36) to conditionally knock out (CKO) or delete the Foxm $1^{f / f l}$ targeted allele in preexisting liver tumors induced by the $\mathrm{DEN} / \mathrm{PB}$ exposure (8). We induced $\mathrm{HCC}$ in mice with 30 weeks of DEN/PB exposure, and then induced $M x$-Cre expression with synthetic double-stranded RNA (dsRNA) to CKO the Foxm $1^{f / f l}$ targeted allele. Mice were then subjected to an additional 10 weeks of PB tumor promotion protocol (Figure 1A). To achieve long-term BrdU labeling of the liver tumors, the mice were then given drinking water containing $1 \mathrm{mg} / \mathrm{ml}$ of BrdU for 4 days $(8,37)$. The $M x$-Cre transgene efficiently deleted the Foxm $1^{f l / f l}$ targeted allele, as evidenced by the absence of detectable nuclear staining of FoxM1 protein in liver tumors of dsRNA CKO Mx-Cre Foxm 1-/- mice compared with control liver tumors (Figure 1, B-D).

We used liver sections stained with $\mathrm{H} \& \mathrm{E}$ to determine the number of tumors per square centimeter of liver tissue (Figure 1, E-G). To calculate the area or size of liver tumors, we used micrographs of H\&E-stained liver tumor sections taken with an Axioplan 2 microscope (Zeiss) and the AxioVision program (version 4.3; Zeiss). After 40 weeks of DEN/PB exposure, control mice displayed hepatic adenomas and HCCs that were larger than $2 \mathrm{~mm}^{2}$ in size (Table 1). Deletion of Foxm 1 in preexisting hepatic tumors in dsRNA CKO $\mathrm{Mx}$-Cre Foxm $1^{-/-}$mice caused a significant reduction in the number of liver tumors larger than $2 \mathrm{~mm}^{2}$ in size compared with control liver tumors after 40 weeks of DEN/PB exposure (Table 1). We next measured tumor cell proliferation by determining the number of hepatic tumor cells that immunostained positive for BrdU incorporation (Figure 1, H-J). Compared with controls, dsRNA CKO $\mathrm{Mx}$-Cre Foxm $1^{-/-}$mice displayed an $80 \%$ reduction in the number of liver tumor cells that stained positive for BrdU after 40 weeks of DEN/PB treatment (Figure $1 \mathrm{~K}$ ). Taken together, these results indicate that deletion of Foxm 1 in preexisting liver tumors significantly diminished proliferation and growth of hepatic cancer cells.

The cell-penetrating WT ARF $26-44$ peptide targets the endogenous mouse FoxM1 protein to the nucleolus of hepatic tumor cells. We previously synthesized a cell-penetrating $\mathrm{ARF}_{26-44}$ peptide fused to $9 \mathrm{~N}$-terminal D-Arg residues $(32,33)$, which efficiently transduced into osteosarcoma U2OS cells and inhibited FoxM1b transcriptional activity (8). Treatment of U2OS cells with $12 \mu \mathrm{M}$ of (D-Arg) ${ }_{9}-\mathrm{ARF}_{26-44}$ (WT $\mathrm{ARF}_{26-44}$ ) peptide fluorescently tagged with tetramethylrhodamine (TMR) targeted nuclear GFP-FoxM1b green fluorescence colocalized with red WT ARF $26-44$ peptide fluorescence in the nucleolus (Figure 2, $\mathrm{C}$ and $\mathrm{D})$. In contrast, GFP-FoxM1b protein remained nuclear in U2OS cells when treated with a TMR fluorescently tagged mutant 
A
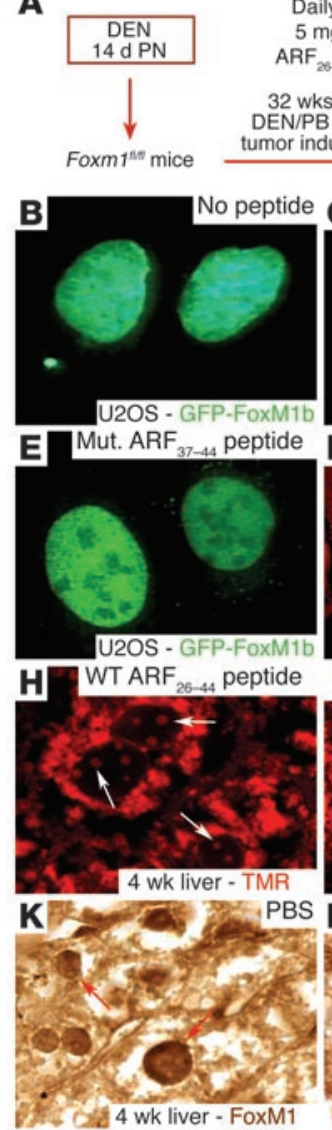

Daily i.p. injections of PBS or $5 \mathrm{mg} / \mathrm{kg}$ cell-penetrating WT ARF $_{26-44}$ peptide or Mut. ARF \begin{tabular}{l|l}
32 wks of & $\begin{array}{l}4 \text { or } 8 \text { wks of ARF } \\
\text { peptide and PB }\end{array}$
\end{tabular} $\mathrm{DEN} / \mathrm{PB}$ liver
tumor induction $\quad \begin{gathered}4 \text { or } \\ \text { peptide and } \mathrm{PB} \\ \text { tumor promotio }\end{gathered}$ $4 \mathrm{~d}$
of BrdU $\begin{gathered}\text { Sacrifice mice } \\ \text { to examine }\end{gathered}$ $\stackrel{\text { of } \mathrm{BrdU}}{\longrightarrow} \begin{gathered}\text { So examine } \\ \text { to } \\ \text { liver tumors }\end{gathered}$
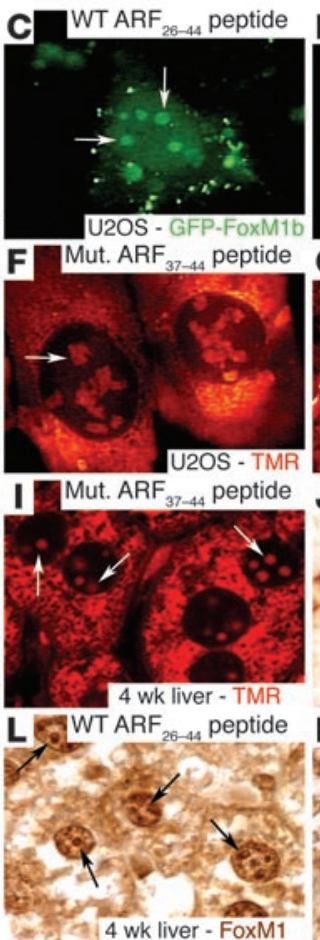
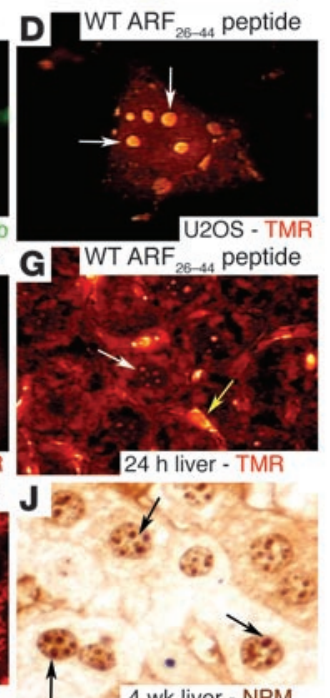

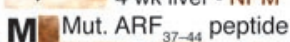

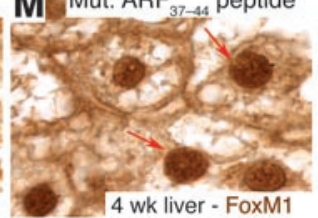

\section{Figure 2}

The WT ARF $_{26-44}$ peptide targets the liver tumor FoxM1 protein to the nucleolus. (A) Experimental design diagram of ARF peptide treatment of liver tumor-bearing mice. Liver tumors were induced in mice with DEN/PB exposure, and then they were subjected to daily i.p. injections of the WT $A R F_{26-44}$ peptide or mutant $\mathrm{ARF}_{37-44}$ peptide (Mut. $\mathrm{ARF}_{37-44}$ peptide) as described in Methods. (B-F) GFP-FoxM1b protein is targeted to the nucleolus by the WT $\mathrm{ARF}_{26-44}$ peptide. U2OS cells were transfected with GFP-FoxM1b expression vector and were either left untreated or incubated for 48 hours with TMR fluorescently tagged WT $\mathrm{ARF}_{26-44}$ peptide $(\mathbf{C}$ and $\mathbf{D})$ or mutant $\mathrm{ARF}_{37-44}$ peptide ( $\mathbf{E}$ and $\mathbf{F}$ ) and then analyzed for GFP (green) or peptide (red) fluorescence. (G) TMR fluorescence labeling revealed that the WT $\mathrm{ARF}_{26-44}$ peptide was localized to the hepatocyte cytoplasm and nucleolus (white arrow) and in the hepatic mesenchymal cells (yellow arrow). ( $\mathbf{H}$ and $\mathbf{I})$ Both mutant $\mathrm{ARF}_{37-44}$ peptide and $\mathrm{WT} \mathrm{ARF}_{26-44}$ peptide are targeted to the hepatocyte cytoplasm and nucleolus (white arrows) as determined by laser confocal microscopy. Immunostaining of tumor sections with antibody specific to either NPM protein (black arrows) (J) or FoxM1 protein (K-M). WT ARF $26-44$ peptide targets tumor FoxM1 to the nucleolus (black arrows), whereas FoxM1 remains nuclear after treatment with mutant $\mathrm{ARF}_{37-44}$ peptide or PBS (red arrows). Magnification: $\times 400$ (B-F and J-M); $\times 200(\mathbf{G})$; and $\times 600(\mathbf{H}$ and $\mathbf{I})$.
(D-Arg) $)_{9}-\mathrm{ARF}_{37-44}$ (mutant $\mathrm{ARF}_{37-44}$ ) peptide (Figure 2E), which lacked the amino acids 26-37 required to interact with the FoxM1b protein (8). Because Arg-rich sequences are sufficient for nucleolar targeting (38), the mutant $\mathrm{ARF}_{37-44}$ peptide fluorescence also localized to the nucleolus of U2OS cells (Figure 2F). We did not observe any signal in the absence of the ARF peptide (data not shown).

Dose-response curve determined that only i.p. injection of $5 \mathrm{mg} / \mathrm{kg}$ body weight or greater of the TMR fluorescently tagged WT $\mathrm{ARF}_{26-44}$ peptide was detectable in cytoplasm and nucleolus of hepatocytes and in hepatic mesenchymal cells at 24 hours after administration (Figure 2G; see Methods). After 32 weeks of DEN/PB liver tumor induction, we subjected Foxm 1 fl/fl mice to daily i.p. injections of $5 \mathrm{mg} / \mathrm{kg}$ body weight of the WT ARF $\mathrm{WR}_{26-44}$ peptide or mutant $A_{R F} F_{37-44}$ peptide for 4 weeks and of $W_{T} A_{R F} F_{26-44}$ peptide for 8 weeks (Figure 2A). After 4 weeks of treatment with TMR fluorescently tagged ARF peptides, laser confocal microscopy of paraffin-embedded mouse liver tumor sections revealed that ARF peptide fluorescence localized to the hepatocyte cytoplasm and nucleolus (Figure 2, H and I) and was uniformly distributed throughout the liver parenchyma (data not shown). The FoxM1 protein staining in $\mathrm{WT} \mathrm{ARF}_{26-44}$ peptide-treated liver tumor sections was partially localized to the nucleolus in hepatic tumor cells (Figure 2L, black arrows), which was similar to the immunostaining pattern of the nucleolar protein nucleophosmin (NPM; Figure 2J, black arrows). In contrast, mutant $\mathrm{ARF}_{37-44}$ peptide- or PBS-treated liver tumor cells displayed only nuclear FoxM1 staining (compare Figure $2 \mathrm{~K}$ and Figure $2 \mathrm{M}$, red arrows). These studies demonstrate that the $\mathrm{WT} \mathrm{ARF}_{26-44}$ peptide reduces in vivo function of FoxM1 by partially targeting the endogenous FoxM1 protein to the nucleolus of hepatic tumor cells.

WT ARF $26-44$ peptide diminishes proliferation and size of liver tumors. We next determined the number of hepatic tumor cells that incorporated BrdU in mice treated with WT ARF 26-44 $_{2}$ peptide, mutant $\mathrm{ARF}_{37-44}$ peptide, or PBS. Significant reduction in BrdU incorporation was found in liver tumors that had been treated with the WT ARF $\mathrm{WL}_{26-44}$ peptide for 4 or 8 weeks compared with mouse liver tumors treated with mutant $\mathrm{ARF}_{37-44}$ peptide or PBS (Figure 3, $\mathrm{A}-\mathrm{K}$ ). Compared with control treatment, treatment with the $\mathrm{WT} \mathrm{ARF}_{26-44}$ peptide for 8 weeks significantly reduced tumor growth and prevented development of HCCs larger than $2 \mathrm{~mm}^{2}$ in size (Table 1). These results indicate that treatment with the $\mathrm{WT} \mathrm{ARF}_{26-44}$ peptide is an effective method with which to reduce proliferation and growth of HCCs.

We previously demonstrated that tumor resistance in Foxm1hepatic tumors was associated with persistent nuclear accumulation of the CDKI protein $\mathrm{p}^{27^{\mathrm{Kip}} 1}$ (8). WT $\mathrm{ARF}_{26-44}$ peptide-treated HCC cells displayed increased nuclear levels of the $\mathrm{p} 27^{\mathrm{Kip} 1}$ protein, which were similar to those found with dsRNA CKO Mx-Cre Foxm $1^{-1-}$ liver tumors (Figure 4, B and E). In contrast, p2 $7^{\mathrm{Kip} 1}$ immunostaining was predominantly cytoplasmic in mutant $\mathrm{ARF}_{37-44}$ peptide- or PBS-treated mouse HCCs (Figure 4, A, C, D, and F). These studies indicate that the $\mathrm{WT} \mathrm{ARF}_{26-44}$ peptide is effective in reducing FoxM1 function in vivo and that nuclear accumulation of $\mathrm{p} 27^{\mathrm{Kip}} 1$ protein was associated with reduced hepatic tumor proliferation.

WT ARF $F_{26-44}$ peptide causes selective apoptosis of hepatic tumor cells. Analysis of H\&E-stained liver tumor sections from mice treated with the $\mathrm{WT} \mathrm{ARF}_{26-44}$ peptide revealed that many of the hepatic 

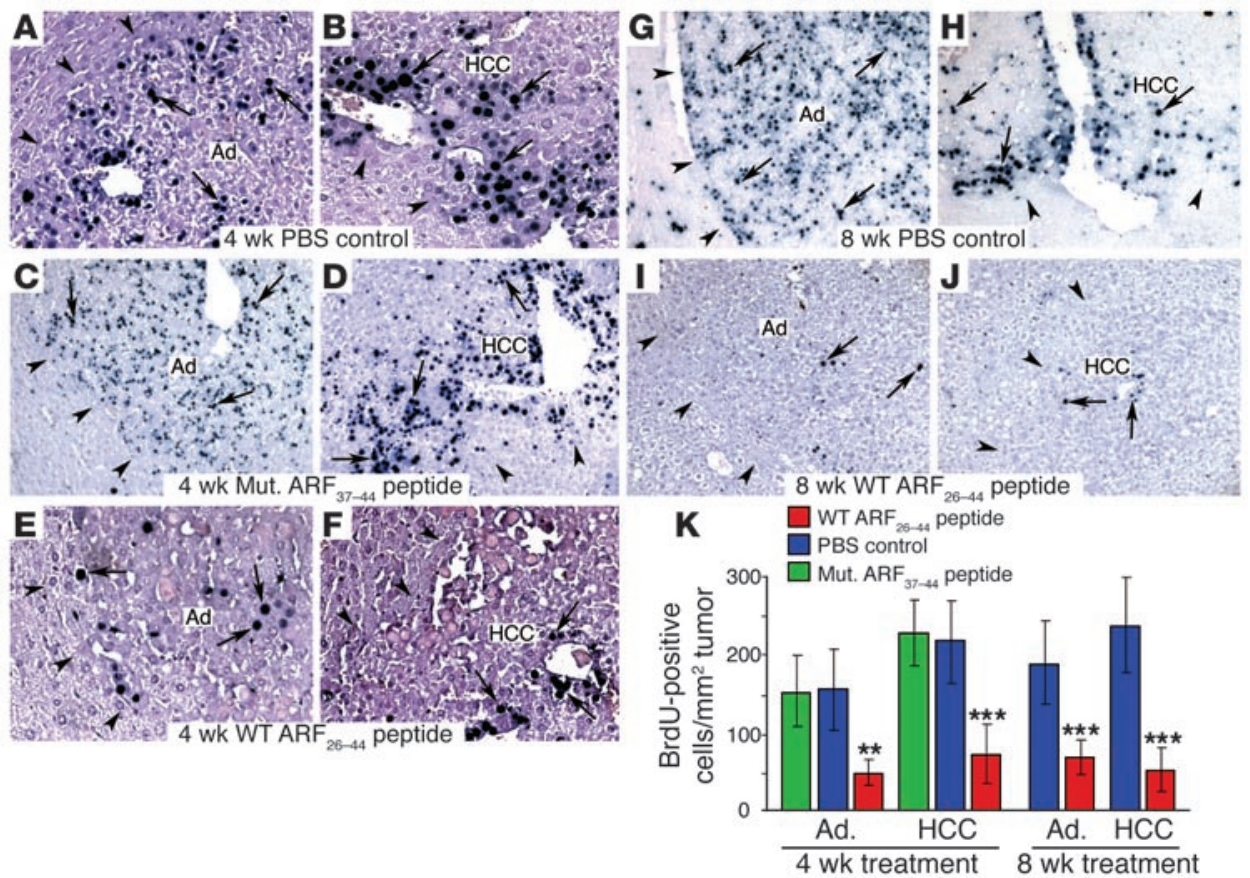

Figure 3

Treatment of mice with the $\mathrm{WT} \mathrm{ARF}_{26-44}$ peptide diminishes proliferation of mouse hepatic tumors. Hepatic tumors were induced in Foxm $1^{\text {tl/f }}$ mice with DEN/PB treatment, and then they were treated with daily i.p. injections of $5 \mathrm{mg} / \mathrm{kg}$ body weight of $\mathrm{WT} \mathrm{ARF}_{26-44}$ peptide or mutant $\mathrm{ARF}_{37-44}$ peptide or $\mathrm{PBS}$ for 4 or 8 weeks as described in the Figure 2A legend. These ARF peptide-treated mice were given drinking water with $1 \mathrm{mg} / \mathrm{ml}$ of BrdU for 4 days before sacrifice in order to obtain long-term labeling of the liver tumors (37). Arrows indicate nuclear staining for BrdU incorporation, and arrowheads show liver tumor margins. (A-J) BrdU incorporation was detected by immunohistochemical staining of liver tumor sections with monoclonal BrdU antibody from mice treated with the indicated ARF peptides. (K) Graph of mean number of BrdU-positive cells per square millimeter liver tumor $( \pm S D)$ following treatment with WT ARF ${ }_{26-44}$ peptide or mutant $\mathrm{ARF}_{37-44}$ peptide or $\mathrm{PBS}$. We calculated the mean number $( \pm \mathrm{SD})$ of BrdU-positive hepatocyte nuclei per square millimeter liver tumor from 3 distinct mice treated with ARF peptide as described in Methods. The asterisks indicate statistically significant changes: ${ }^{* \star} P \leq 0.01$ and ${ }^{* \star *} P \leq 0.001$. Magnification: $\times 200(\mathbf{A}-\mathbf{J})$.

adenomas and HCC tumor cells stained red and exhibited disruption of nuclear membrane, which is indicative of apoptosis (Figure 5, A-F). These red-staining cells were found neither in the surrounding normal liver tissue (Figure $5, \mathrm{~A}-\mathrm{F}$ ) nor in hepatic tumors from mice treated with either the mutant $\mathrm{ARF}_{37-44}$ peptide or $\mathrm{PBS}$ (Figure 5, G-L). Furthermore, these apoptotic tumor cells were not apparent in deficient livers in dsRNA CKO Mx-Cre Foxm 1-/- mice (Figure 1, E-G), a finding consistent with our previous tumor studies with Alb-Cre Foxm 1 $1^{-1-}$ livers (8).

We used a fluorescence-based TUNEL assay to determine that mouse HCC cells treated with WT ARF $26-44$ peptide exhibited a significant, $22 \%$ increase in apoptosis (Figure 6, A, B, and E). In contrast, very few apoptotic HCC cells were found after treatment with mutant $\mathrm{ARF}_{37-44}$ peptide or PBS (Figure 6, C-E). Immunostaining of liver tumor sections with proteolytically cleaved activated caspase-3 protein confirmed this selective apoptosis of mouse HCC cells treated with $\mathrm{WT} \mathrm{ARF}_{26-44}$ peptide with no proapoptotic staining in the adjacent normal liver tissue (Figure 6, F-H). These studies show that the WT ARF peptide selectively induces apoptosis of HCC cells without damaging adjacent normal hepatocytes.

DEN/PBtreatmentinducedhighlyproliferative HCCsin Arf/-Rosa26-FoxM1b $T g$ mice that were responsive to $W T A R F_{26-44}$ peptide treatment. We previ- ously showed that the ARF tumor suppressor targets the FoxM1b protein to the nucleolus and inhibits its transcriptional function (8). Furthermore, we showed that increased expression of the human FoxM1b cDNA in Rosa26-FoxM1b Tg mice (34) stimulated development and progression of prostate cancers in both TRAMP/Rosa26-FoxM1b and $L A D Y / R o s a 26-F o x M 1 b$ double$\mathrm{Tg}$ mice (35). In order to develop a new genetic model of HCC that is highly dependent on the FoxM1b transcription factor, we crossed the Rosa26-FoxM1b Tg mice into the Arf/- mouse background. After 33 weeks of DEN/PB treatment, Arf/Rosa26-FoxM1b Tg mice developed highly proliferative HCCs, and their HCC cells displayed a proliferation rate of 6,000 BrdU-positive cells per square millimeter tumor (Figure 7J), which is approximately 30 -fold greater than that observed in DEN/PBinduced HCCsin WT mice (Figure 3K; $200 \mathrm{BrdU}$-positive cells per $\mathrm{mm}^{2}$ tumor). The DEN/PB-treated Arf/Rosa26-FoxM1b Tg livers also exhibited development of necrosis and fibrosis/cirrhosis (data not shown). These HCC tumor-bearing Arf $/$ Rosa26-FoxM1b Tg mice were subjected to daily treatment with either the WT ARF $26-44$ peptide or mutant $\mathrm{ARF}_{37-44}$ peptide for 4 weeks. In Arf ${ }^{\prime-}$ Rosa26-FoxM1b Tg mice, WT $\mathrm{ARF}_{26-44}$ peptide treatment resulted in a significant, $84 \%$ reduction in BrdU labeling of HCC cells compared with treatment of these mice with either mutant $\mathrm{ARF}_{37-44}$ peptide or PBS (Figure 7, A-C and J). Red-staining HCC cells with disruption of nuclear membrane indicative of apoptosis were found in H\&E-stained liver tumor sections from Arf $/$ Rosa26-FoxM $1 b \mathrm{Tg}$ mice treated with the WT ARF ${ }_{26-44}$ peptide but not from those treated with mutant $\mathrm{ARF}_{37-44}$ peptide or PBS (Figure 7, D-F). We used a fluorescence-based TUNEL assay to determine that Arf/- Rosa26FoxM1b Tg HCC cells treated with WT ARF ${ }_{26-44}$ peptide exhibited a $42 \%$ increase in apoptosis (Figure $7 \mathrm{~K}$ ), which was twice as high as in liver tumors from WT mice (Figure 6E). Furthermore, TUNELpositive cells were restricted to the HCC region (white arrowheads) and were not detected in adjacent normal liver tissue (Figure 7I). In contrast, very few apoptotic HCC cells were found after treatment of Arf/- Rosa26-FoxM1b Tg mice with mutant $\mathrm{ARF}_{37-44}$ peptide or PBS (Figure 7, G, H, and K). These Arf/- Rosa26-FoxM1b Tg liver tumor studies show that the WT ARF $26-44$ peptide is effective in diminishing BrdU labeling of highly proliferative HCC cells and selectively induces apoptosis of HCC cells in these mice without damaging adjacent normal liver tissue.

WT ARF $F_{26-44}$ peptide inhibits angiogenesis of the HCC region. Angiogenesis is critical to mediating HCC growth, and the endothelial 

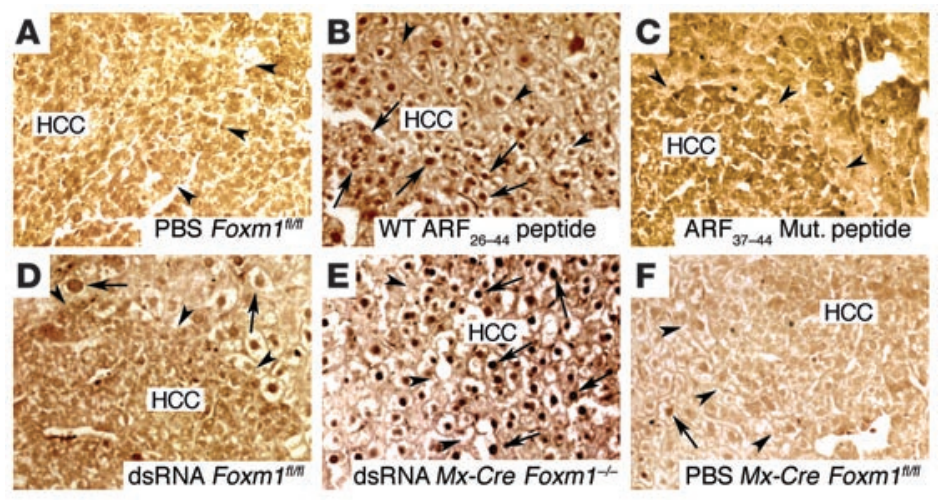

Figure 4

WT $\mathrm{ARF}_{26-44}$ peptide treatment causes nuclear accumulation of p27Kip1 protein in mouse HCC tumors. (A-F) Nuclear accumulation of p27 ${ }^{\text {Kip1 }}$ protein in HCC tumors from WT ARF $26-44$ peptide-treated mice and dsRNA Mx-Cre Foxm $1^{-1-}$ mice. Hepatic tumors were induced in Foxm $1^{\text {fllfl }}$ mice with DEN/PB treatment, and then they were treated with daily i.p. injections of $5 \mathrm{mg} / \mathrm{kg}$

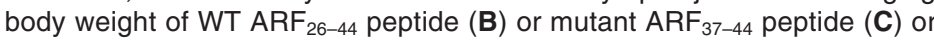
PBS (A) for 4 weeks as described in the Figure 3A legend. (D-F) The Foxm1 gene was genetically deleted in preexisting liver tumors of dsRNA Mx-Cre Foxm $1^{-/-}$mice versus control dsRNA Foxm $1^{f / \mid f l}$ and PBS Mx-Cre Foxm $1^{f|l| f \mid}$ as described in the Figure 1 legend. Liver tumor sections from the indicated mice were immunohistochemically stained with the $\mathrm{p} 27^{\mathrm{Kip} 1}$ antibody. Arrows indicate nuclear staining for $\mathrm{p} 27^{\mathrm{Kip} 1}$ protein, and arrowheads show liver tumor margins. Magnification, $\times 200$.

cells of new HCC capillaries exhibit expression of the CD34 protein (39-41). Abundant CD34 staining was found in endothelial cells of $\mathrm{HCC}$ regions in $\mathrm{PBS}$ or mutant $\mathrm{ARF}_{37-44}$ peptide-treated mice (Figure 8, A and B) and from dsRNA CKO Mx-Cre Foxm 1-1mice (Figure $8 D$ ). In contrast, expression of the $\mathrm{CD} 34$ protein was not detected in the $\mathrm{HCC}$ region from $\mathrm{WT} \mathrm{ARF}_{26-44}$ peptide-treated


treatment was preventing HCC angiogenesis, which was likely caused by apoptosis of new HCC endothelial cells (Figure 6B; small apoptotic cells). In order to determine whether $\mathrm{WT} \mathrm{ARF}_{26-44}$ peptide induces apoptosis of endothelial cells, we treated human microvascular endothelial cells (HMEC-1 cells) for 48 hours with $100 \mu \mathrm{M}$ of $\mathrm{WT} \mathrm{ARF}_{26-44}$ peptide or mutant $\mathrm{ARF}_{37-44}$ peptide or with PBS and then assayed for apoptosis as described in Methods. This analysis revealed that $\mathrm{WT} \mathrm{ARF}_{26-44}$ peptide treatment induced a significant increase in apoptosis of HMEC-1 cells compared with treatment with mutant $\mathrm{ARF}_{37-44}$ peptide or PBS (Figure 8E). These studies suggest that $\mathrm{WT} \mathrm{ARF}_{26-44}$ peptide is able to induce apoptosis of endothelial cells, which contributes to WT ARF peptidemediated reduction in HCC angiogenesis.

Reduced levels of the antiapoptotic survivin protein contribute to $W_{T A R F} F_{26-44}$ peptide-induced HCC apoptosis. We have shown that FoxM1 regulates transcription of survivin (26), which complexes with aurora B kinase to mediate its proper localization during mitosis (42-44). Survivin is also a member of the inhibitor of apoptosis (IAP) protein family and is selectively overexpressed in tumor cells to prevent their apoptosis (45-48). Mutant $\mathrm{ARF}_{37-44}$ peptide- or PBS-treated liver tumors displayed abundant nuclear and cytoplasmic staining of survivin protein (Figure 8, E and F), and survivin expression was restricted to the mouse HCC region (data not shown). Nuclear levels of survivin were diminished in $\mathrm{HCC}$ regions from $\mathrm{WT} \mathrm{ARF}_{26-44}$ peptide-treated and dsRNA CKO Mx-Cre Foxm $1^{-/-}$mice (Figure 8, G and H). Western blot analysis revealed that Foxm $1^{-/-}$liver tumors displayed a $60 \%$ decrease in expression of survivin protein (Figure 8, I and J), and no apoptosis was detected in these FoxM1-deficient liver tumors (Figure 1, E-G). A more drastic, 90\% decrease in survivin protein levels was found in hepatic tumors from WT $\mathrm{ARF}_{26-44}$ peptide-treated mice (Figure 8, H-J). Our hepatoma data presented below (Figure 9) support the hypothesis that $\mathrm{WT} \mathrm{ARF}_{26-44}$ peptide treatment results in hypomorphic levels of FoxM1 activity, which reduces expression of mitotic regulators to levels that are insufficient to properly execute mitosis leading to apoptosis, whereas depleting FoxM1 levels leads to mitotic arrest.

The nucleolar nucleophosmin/B23 (NPM/B23) protein $(49,50)$ and the p53 negative regulator, $\mathrm{Mdm} 2$ protein $(51)$, associated with the ARF tumor suppressor protein through ARF amino acid sequences $1-15$ and 26-37, which partially overlapped with our WT $\mathrm{ARF}_{26-44}$ peptide sequence. Despite this partial overlap, Western blot analysis enabled us to determine that neither $\mathrm{WT} \mathrm{ARF}_{26-44}$ peptide treatment nor Foxm1 deficiency altered expression of NPM, p53, or Mdm2 proteins in liver tumor extracts (Figure 8, J and $\mathrm{K}$, and data not shown), suggesting that the $\mathrm{ARF}_{26-44}$ peptide sequence was insufficient to influence their expression levels in vivo. The proapoptotic Bcl-2 family member p53-upregulated modifier of apoptosis (PUMA) is a transcriptional target gene of p53 that is essential for both p53 transcriptional and cytoplasmicdependent apoptosis (52-55). Western blot analysis showed that neither WT $\mathrm{ARF}_{26-44}$ peptide nor mutant $\mathrm{ARF}_{37-44}$ peptide treatment caused significant change in expression of PUMA in liver tumor extracts (Figure 8K), suggesting that this apoptosis of HCC cells did not involve the p53/PUMA proapoptotic pathway.

WT ARF peptide-induced apoptosis of human hepatoma HepG2 cells correlates with diminished expression of survivin, PLK1, and aurora B kinase. We used the TUNEL assay to determine that human hepatoma HepG2 cells (Figure 9, A-E), PLC/PRF/5 cells that express mutant p53 protein, and p53-deficient Hep3B cells exhibited 50\% apoptosis after 24 hours of treatment with $25 \mu \mathrm{M}$ of WT $\mathrm{ARF}_{26-44}$ peptide (Figure 9E), whereas only low levels of apoptosis were detected in these cells following treatment with mutant $\mathrm{ARF}_{37-44}$ peptide or PBS (Figure 9E). Diminished levels of p53 protein through p53 siRNA silencing of HepG2 cells did not influence apoptosis in response to $\mathrm{WT} \mathrm{ARF}_{26-44}$ peptide treatment (Figure 9F). In addition, p53 protein levels were unaltered in HepG2 cells after 24 hours of treatment with WT $\mathrm{ARF}_{26-44}$ or mutant $\mathrm{ARF}_{37-44}$ peptide (Figure 9F). Furthermore, protein expression of the $\mathrm{p} 53$ downstream proapoptotic target PUMA was unchanged in HepG 2 cells in response to increasing concentrations of the $\mathrm{WT} \mathrm{ARF}_{26-44}$ peptide (Figure 9I). These results suggest that WT ARF $_{26-44}$ peptide-induced apoptosis was independent of the p53/PUMA proapoptotic pathway (52-55). Moreover, HepG2 cells in which FoxM1 levels were depleted by electroporation of FoxM1 no. 2 siRNA duplexes were resistant to apoptosis in response to WT $\mathrm{ARF}_{26-44}$ peptide treatment (Figure $9 \mathrm{~F}$ ), suggesting that induction of apoptosis by the WT ARF peptide was dependent on FoxM1 levels.

Tumor cells are known to express high levels of the mitotic regulators PLK1, aurora B kinase, and survivin proteins, which function to prevent their apoptosis $(45,48,56-62)$. Previous studies demonstrated that U2OS cells transfected with siFoxM1 \#2 duplex were blocked in mitotic progression and exhibited undetectable levels of FoxM1 and its downstream target mitotic regulators PLK1, aurora B kinase, and survivin (26). Consistent with these 

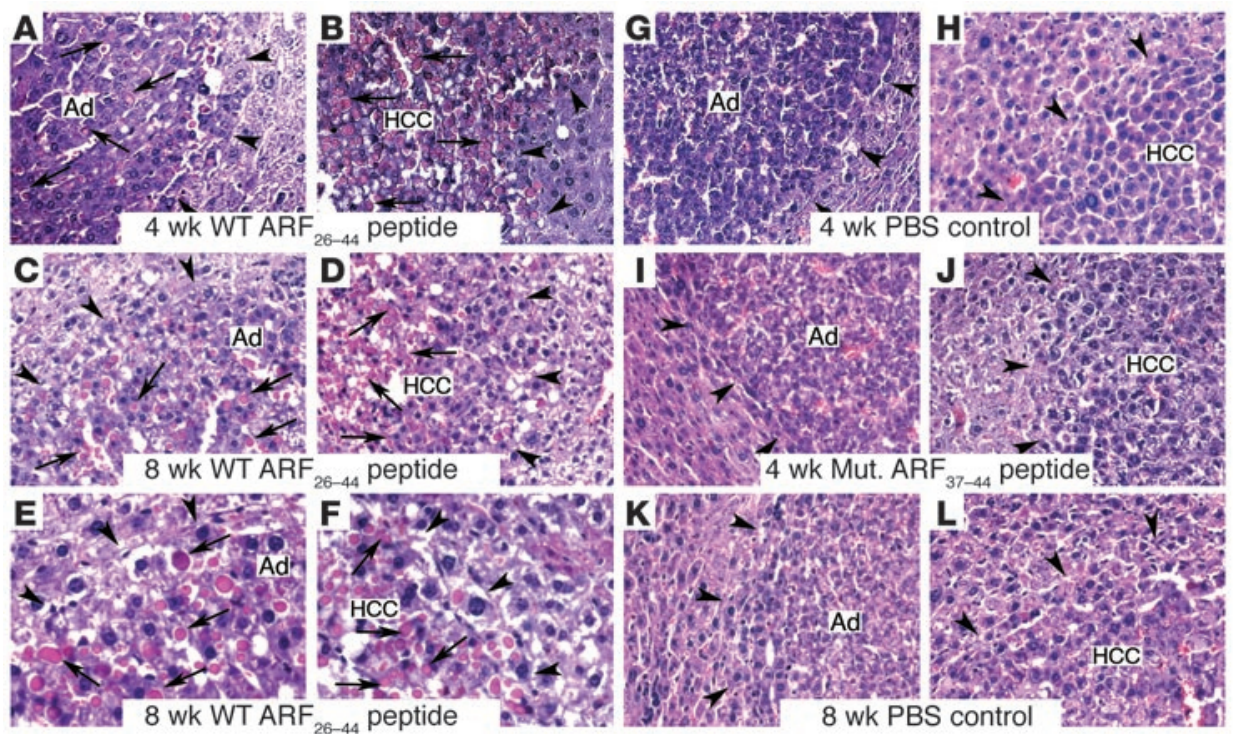

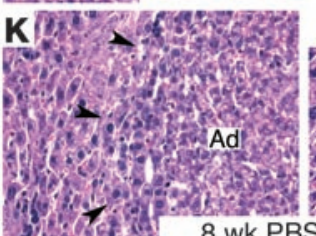

8 wk PBS control

Figure 5

$\mathrm{H} \& \mathrm{E}$-stained liver tumors from mice treated with $\mathrm{WT}_{\mathrm{ARF}} \mathrm{AR}_{24}$ peptide. Hepatic tumors were induced in Foxm $1^{\text {fllfl }}$ mice with DEN/PB treatment, and then they were treated with daily i.p. injections of $5 \mathrm{mg} / \mathrm{kg}$ body weight of WT $A^{2} F_{26-44}$ peptide or mutant $A_{R F} F_{37-44}$ peptide for 4 or 8 weeks (see Figure $2 \mathrm{~A}$ legend). Arrows indicate red-staining cells undergoing apoptosis, and arrowheads show liver tumor margins. (A-F) H\&E-stained liver tumor sections from WT ARF ${ }_{26-44}$ peptide-treated mice revealed that many of the hepatic adenomas and HCC tumor cells stained red and were rounded up, which is indicative of apoptosis. $\mathbf{E}$ and $\mathbf{F}$ are higher-magnification images of $\mathbf{C}$ and $\mathbf{D}$. No red-staining apoptotic cells were found in either the surrounding, normal liver tissue or in liver tumors from dsRNA CKO Mx-Cre Foxm1-l- mice (see Figure 1, E-G). (G-L) No red-staining tumor cells were found in H\&Estained liver tumor sections from mice treated with either PBS or mutant $\mathrm{ARF}_{37-44}$ peptide. Magnification, $\times 200($ A-D and G-L); ×400 (E and F).

studies, FoxM1-depleted HepG2 cells exhibited undetectable protein levels of survivin, PLK1, and aurora B kinase (Figure 9G). We electroporated HepG2 cells with siFoxM1 \#2 or control p27 $7^{\mathrm{Kip} 1}$ siRNA (siP27) and grew the cells in culture for 2 days to allow for siRNA silencing, and then $2 \times 10^{5}$ HepG 2 cells were plated in triplicate, and viable HepG2 cells were counted at 2, 3, 4, or 5 days following electroporation. These cell-growth studies showed that FoxM1-deficient HepG2 cells were unable to grow in culture and gradually detached from the plate with time in culture (Figure $9 \mathrm{H}$ ). In contrast, HepG 2 cells treated with $\mathrm{WT} \mathrm{ARF}_{26-44}$ peptide exhibited a less severe reduction in levels of survivin (50\%), PLK1 (80\%), and aurora B kinase (80\%) proteins compared with controls (Figure 9I). We also determined a growth curve of HepG2 cells at 1, 2, or 3 days following treatment with $\mathrm{WT} \mathrm{ARF}_{26-44}$ peptide, mutant $\mathrm{ARF}_{37-44}$ peptide, or PBS. Although the $\mathrm{WT} \mathrm{ARF}_{26-44}$ peptide-treated HepG2 cells displayed $50 \%$ apoptosis (Figure $9 \mathrm{E}$ ), they were able to sustain the number of cells initially plated $\left(2 \times 10^{5}\right)$, suggesting that the WT ARF peptide-treated cells were able to proceed through the cell cycle (Figure 9J). These results are consistent with recent studies in which hypomorphic levels of FoxM1 protein (40\% of WT FoxM1 levels) in breast cancer cell lines transfected with a different Foxm1 siRNA duplex reduced expression of mitotic regulators to levels that are insufficient to properly execute mitosis, leading to mitotic catastrophe and apoptosis (63). Based on these findings, we propose the hypothesis that $\mathrm{WT}_{\mathrm{ARF}_{26-44}}$ peptide treatment causes hypomorphic levels of FoxM1 activity, leading to apoptosis, whereas depleting FoxM1 levels results in mitotic arrest. However, we have not ruled out other possibilities.

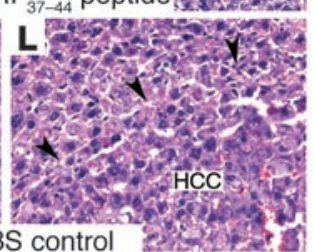

\section{Discussion}

Patients with HCCs have poor prognoses because late detection and high frequency of tumor recurrence render current HCC therapy ineffective (1). One of the potentially curative approaches in HCC therapy is based on interfering with HCC progression by blocking cell division and selectively inducing tumor cell apoptosis. In this study, we demonstrated that FoxM1 is required for proliferation of mouse liver cancer cells during tumor progression. To pharmacologically reduce in vivo activity of FoxM1 in HCC, mice were subjected to daily injections with a cell-penetrating $\mathrm{ARF}_{26-44}$ peptide inhibitor of FoxM1 function. After 4 weeks of ARF peptide treatment, FoxM1 protein was partially localized to the nucleolus of HCC cells, and these hepatic tumor cells displayed reduced proliferation and angiogenesis with selective induction of HCC apoptosis (Figure 9K). Reduced tumor cell proliferation in Foxm1-deficient and WT $\mathrm{ARF}_{26-44}$ peptide-treated tumors was associated with nuclear accumulation of the CDKI protein $\mathrm{p} 27^{\mathrm{Kip}}$, which is known to negatively regulate proliferation of HCC cells in mouse liver cancer models (64). In contrast, mice treated with the cell-penetrating mutant $\mathrm{ARF}_{37-44}$ peptide, which is missing ARF sequences required for interaction with the FoxM1 protein (8), did not change nuclear localization of FoxM1 protein and failed to influence proliferation, apoptosis, or angiogenesis of HCC cells. Our current studies show that treatment with the WT $\mathrm{ARF}_{26-44}$ peptide effectively diminishes proliferation and induces apoptosis of HCC cells by reducing FoxM1 function in vivo.

In order to develop a new genetic model of HCC that is highly dependent on FoxM1b transcription factor, we crossed Rosa26-FoxM1b $\mathrm{Tg}$ mice, which ubiquitously expressed the human FoxM1b cDNA transgene (34), into the Arf/- mouse background. Use of the Arf/Rosa26-FoxM1b Tg mice allowed us to overexpress the FoxM1b protein and eliminated ARF tumor suppressor inhibition of the FoxM1b protein. After 33 weeks of DEN/PB treatment, Arf ${ }^{\prime-}$ Rosa26-FoxM1b Tg mice exhibited highly proliferative HCC cells that displayed approximately 30 -fold more BrdU incorporation than that found in WT mice in which liver tumors were induced by $\mathrm{DEN} / \mathrm{PB}$ exposure. After 4 weeks of treatment with the $\mathrm{WT} \mathrm{ARF}_{26-44}$ peptide, the Arf ${ }^{\prime-}$ Rosa26-FoxM1b Tg mice exhibited a significant reduction in BrdU incorporation, and apoptosis was induced in twice the number of HCC cells. The results suggest that these highly proliferative hepatic tumors with increased levels of FoxM1b protein are more susceptible to $\mathrm{WT}_{\mathrm{ARF}_{26-44}}$ peptide-induced apoptosis and display diminished proliferation of HCC cells.

Increased expression of antiapoptotic survivin protein in human HCC and stage II colorectal carcinomas correlates with reduced apoptosis, poor patient outcome, and tumor recurrence follow- 

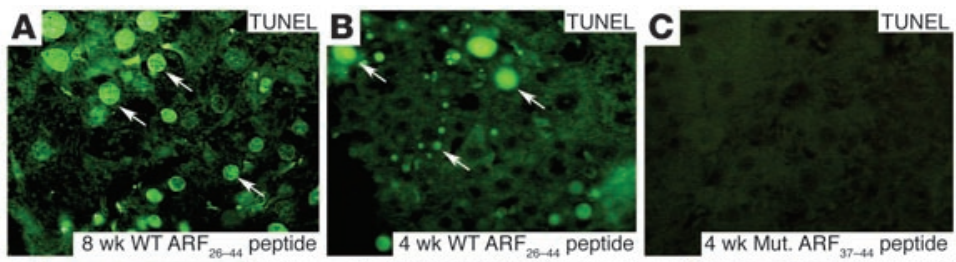
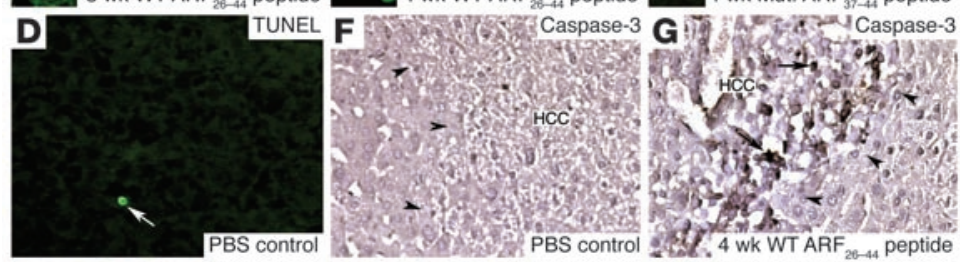

E

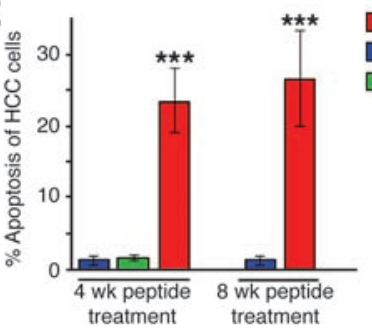

\section{Figure 6}

WT $\mathrm{ARF}_{26-44}$ peptide treatment induces selective apoptosis of mouse HCC. (A-D) Liver tumor sections were stained for apoptotic cells using the TUNEL assay. Mice treated with WT $\mathrm{ARF}_{26-44}$ peptide for either 4 or 8 weeks exhibited a significant increase in tumor cell apoptosis as evidenced by TUNEL-positive staining (green fluorescence; indicated by white arrows), whereas mutant $\mathrm{ARF}_{37-44}$ peptide- or PBS-treated mice displayed very few apoptotic cells in HCC tumors. (E) Quantitation of TUNEL-positive staining cells. Triple asterisks indicate statistically significant change at ${ }^{\star * *} P \leq 0.001$. (F-H) Selective apoptosis is detected in HCC tumor cells in mice treated with WT ARF $_{26-44}$ peptide by immunostaining with antibody specific to proteolytically cleaved activated caspase- 3 protein. Arrows indicate nuclear staining for activated caspase-3 protein, and arrowheads show liver tumor margins. Magnification, $\times 400$ (A-D and H); $\times 200$ (F and G). ing treatment (46-48). Proliferating tumor cells are known to constitutively express high levels of the mitotic regulators PLK1, aurora B kinase, and survivin proteins, while normal cells only express these proteins in the $G_{2}$ phase and mitosis. Experiments that reduced expression of these mitotic regulators with siRNA transfection or reduced their activity with specific kinase inhibitors caused increased apoptosis and diminished growth of cancer cells $(45,48,56-62)$. We found that HCC regions and HepG2 cells expressed high levels of PLK1, aurora B kinase, and survivin, all of which are FoxM1 transcriptional target genes (26). Previous studies demonstrated that Foxm $1^{-/-}$mouse embryonic fibroblasts or FoxM1-depleted U2OS cells were blocked in mitotic progression, failed to undergo apoptosis, and were associated with undetectable levels of PLK1, aurora B kinase, and survivin (26). Interestingly, we showed that WT ARF $26-44$ peptide treatment induced significant apoptosis in human hepatoma HepG2 cells, PLC/PRF/ 5 cells that express mutant p53 protein, and p53-deficient Hep3B cells. We also showed that siRNA silencing of FoxM1 levels in HepG2 cells reduced apoptosis in response to $\mathrm{WT} \mathrm{ARF}_{26-44}$ peptide treatment, suggesting that ARF-dependent apoptosis of this hepatoma cell line required FoxM1 expression. Furthermore, we showed that FoxM1-depleted HepG2 cells failed to grow in culture and displayed undetectable levels of the mitotic regulators PLK1, aurora B kinase, and survivin proteins (Figure 9). In contrast, treatment of HepG 2 cells with the $\mathrm{WT} \mathrm{ARF}_{26-44}$ peptide resulted in less drastic reductions in expression of survivin, PLK1, and aurora B kinase protein and allowed growth of HepG2 cells in culture but resulted in a significant induction of apoptosis (Figure 9). Consistent with these findings, published studies demonstrated that hypomorphic levels of FoxM1 protein (40\% of WT FoxM1 levels) in breast cancer cell lines transfected with a different Foxm1 siRNA duplex reduced expression of mitotic regulators to levels that are insufficient to properly execute mitosis, leading to mitotic catastrophe and apoptosis (63). Taken together, our results suggest that WT $\mathrm{ARF}_{26-44}$ peptide treatment of cancer cells results in partial inhibition of Foxm 1 activity, leading to mitotic catastrophe and apopto- sis caused by reducing expression of the mitotic regulators PLK1, aurora B kinase, and survivin proteins to levels that are insufficient for proper mitotic progression.

Angiogenesis of HCC cells is a critical event that serves to increase blood supply to the growing tumor, and CD34 protein is expressed on new sinusoid-like endothelial cells of HCC capillaries (39-41). Mice treated with our $\mathrm{WT} \mathrm{ARF}_{26-44}$ peptide failed to develop new CD34-positive endothelial cells in HCC capillaries (Figure 8C), whereas HCC angiogenesis was not affected in dsRNA CKO $\mathrm{Mx}$-Cre Foxm $1^{-1-}$ mice. One explanation for the difference between these mice is that the $\mathrm{WT} \mathrm{ARF}_{26-44}$ peptide may also be inducing apoptosis of CD34-positive endothelial cells in HCC capillaries, thus preventing angiogenesis of $\mathrm{HCC}$ regions required for tumor growth and expansion (Figure $9 \mathrm{~K}$ ). This is supported by the fact that $\mathrm{WT} \mathrm{ARF}_{26-44}$ peptide treatment induces apoptosis of HMEC-1 cells in vitro (Figure $8 \mathrm{E}$ ). Although the $\mathrm{WT} \mathrm{ARF}_{26-44}$ peptide induces apoptosis of HepG2 cells in vitro, we cannot rule out the possibility that this WT ARF peptide is also inducing apoptosis of HCC cells by preventing tumor angiogenesis, thus limiting blood supply required for efficient growth of HCCs.

The WT ARF $26-44$ peptide sequences required to inhibit Foxm1 function do not completely overlap with ARF coding regions essential to inactivating other cell-cycle regulators. For example, both amino acid regions $1-14$ and $26-37$ of the ARF protein are required for association and nucleolar targeting of the p53-negative regulator $\mathrm{Mdm} 2$ protein (65) and the NPM/B23 protein $(49,50)$. Consistent with the specificity of our WT ARF peptide treatment of mice, we found no changes in liver tumor expression of Mdm2, p53, or NPM/B23 proteins in vivo, and apoptosis was independent of increased expression of PUMA, a p53 target gene required for mediating apoptosis (52-55). The ARF tumor suppressor protein also mediates nucleolar targeting of both the proliferation-specific E2F1 and c-Myc transcription factors (11-14). However, there is no overlap with our $\mathrm{WT}_{\mathrm{ARF}} \mathrm{Ab-44}_{2}$ peptide sequence or the $\mathrm{ARF}$ sequences necessary for association with the E2F1 (ARF sequences 6-10 and 21-25) protein (66) and c-Myc (ARF sequences 1-14) protein (12). 

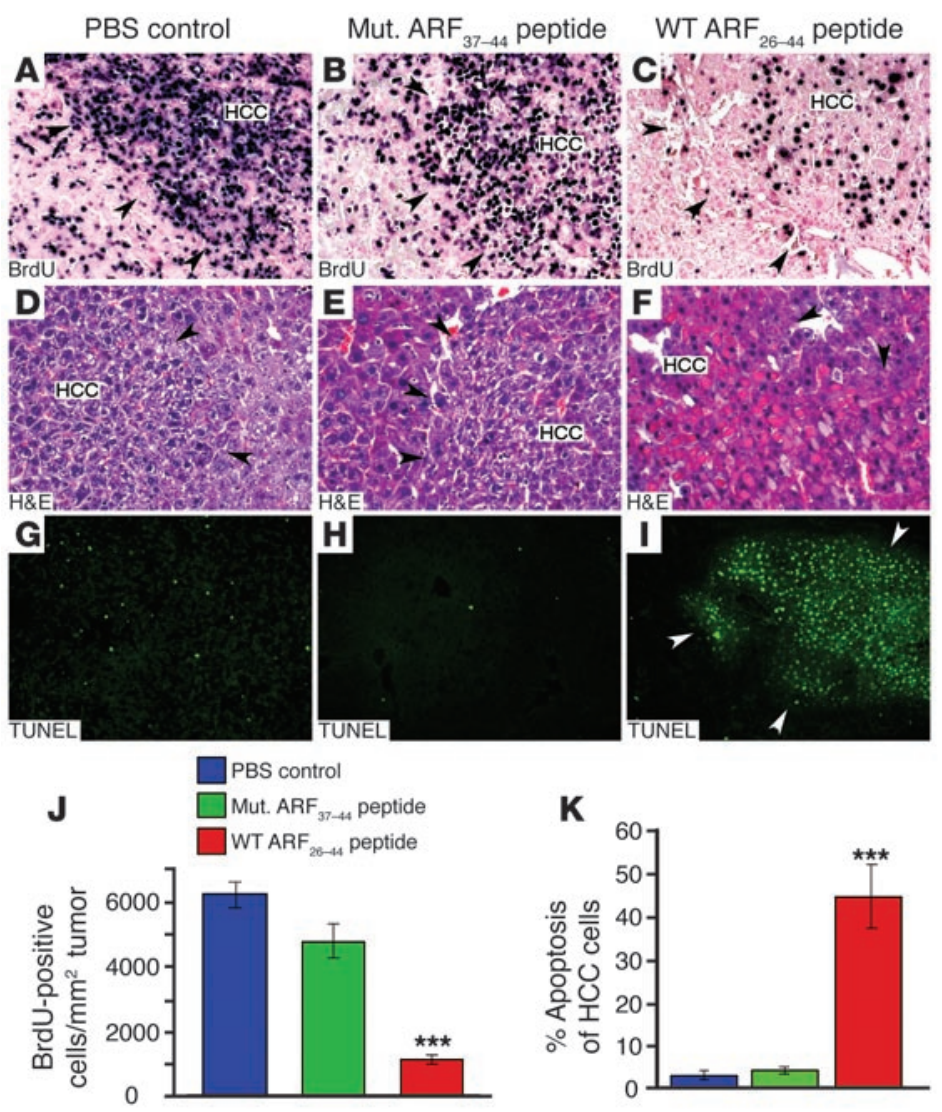

$\mathbf{K}$

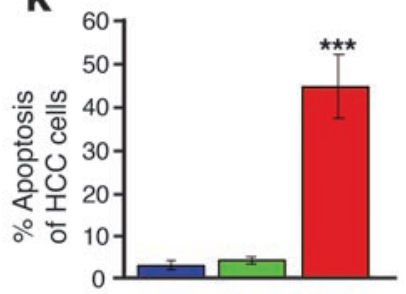

\section{Figure 7}

WT $\mathrm{ARF}_{26-44}$ peptide treatment reduces proliferation and increases apoptosis of HCCs, which were induced in $\mathrm{Arf}^{-/-}$ Rosa26-FoxM1b Tg mice by DEN/PB. Highly proliferative HCC tumors were induced in Arf ${ }^{-}$Rosa26-FoxM1b Tg mice following 33 weeks DEN/PB treatment. The Arf ${ }^{-1}$ Rosa26-FoxM1b $\mathrm{Tg}$ mice received daily i.p. injections of the $\mathrm{WT}_{\mathrm{ARF}} \mathrm{F}_{26-44}$ peptide (inhibitor of FoxM1 function) or mutant $\mathrm{ARF}_{37-44}$ peptide or PBS for 4 weeks. (A-C) Liver tumor sections were subjected to immunohistochemical staining with BrdU monoclonal antibody to determine HCC proliferation. Liver tumor sections were histologically stained with H\&E ( $D$ and $\mathbf{E}$ ) to identify red apoptotic cells or stained for apoptosis using the TUNEL assay (G-I). Black arrowheads indicate the boundaries of the HCC tumor, and white arrowheads (I) indicate the boundary of the HCC region. (J) We counted the BrdU-positive cells in HCCs and used this information to calculate the number of BrdU-positive cells per square millimeter liver tumor tissue $( \pm S D)$. (K) We counted the TUNEL-positive cells in HCCs and used this information to calculate the percent $\mathrm{HCC}$ apoptosis $( \pm \mathrm{SD})$. $P$ values calculated by Student's $t$ test: ${ }^{* *} P \leq 0.001$. Magnification: $\times 200$ $(\mathbf{A}-\mathbf{F}) ; \times 100(\mathbf{G}-\mathbf{I})$.
Cotransfection assays in U2OS cells demonstrated that expression constructs containing ARF 26-37 sequences were unable to effectively inhibit FoxM1b transcriptional activity, suggesting that inhibition of FoxM1 function requires the entire $\mathrm{ARF}_{26-44}$ peptide sequence (data not shown). Furthermore, the in vitro experiments with FoxM1-deficient HepG2 cells showed a clear relationship between FoxM1 and WT $\mathrm{ARF}_{26-44}$ peptide-mediated apoptosis. Moreover, a recent study has shown that translation initiation produces an ARF protein product initiating at methionine amino acid residue 45 and that this $\mathrm{N}$-terminal-truncated ARF protein is localized to the mitochondria and induces caspase-independent cell death (67). Because these $\mathrm{ARF}_{26-44}$ peptide sequences are not contained within this $\mathrm{N}$-terminal-truncated ARF polypeptide, the $\mathrm{WT} \mathrm{ARF}_{26-44}$ peptide utilizes a mechanism that is distinct from the caspase-independent function of this N-terminal-truncated ARF peptide. Based on these studies, the $\mathrm{WT} \mathrm{ARF}_{26-44}$ peptide will specifically reduce Foxm 1 function in vivo to limit growth of HCC and induce $\mathrm{HCC}$ apoptosis without diminishing the function of other known inhibitory targets of the ARF tumor suppressor protein.

After i.p. injection, the absorbed $\mathrm{WT} \mathrm{ARF}_{26-44}$ peptide enters the portal circulation and then flows to the hepatic sinusoid capillaries, which are lined with fenestrated endothelial cells that allow efficient delivery of the ARF peptide to the underlying hepatocytes and hepatic mesenchymal cells (68). However, $\mathrm{WT} \mathrm{ARF}_{26-44}$ peptide treatment of mice did not cause side effects because it could not transverse the endothelial cell barrier of blood vessels to intestinal, colonic, pulmonary, pancreatic, or kidney epithelial cells (data not shown). Likewise, ARF peptide fluorescence also remained in the vessel endothelial cells of bone marrow, spleen, and thymus yet was undetectable in the hematopoietic cells of these organs, which correlated with normal distribution of white and red blood cells in mice treated with this WT $\mathrm{ARF}_{26-44}$ peptide (data not shown). Administration of $\mathrm{WT} \mathrm{ARF}_{26-44}$ peptide by i.p. injection is therefore a selective method for hepatic delivery of this ARF peptide in vivo to limit liver tumor progression and selectively induce apoptosis of HCC cells.

\section{Methods}

$M x$-Cre-mediated deletion of the Foxm $1^{\text {fl/fl }}$ allele in mouse liver tumors induced by DEN/PB exposure. Generation of C57BL/6 mice containing Foxm $1^{f / f l}$ was described previously (25), and they were bred into the C57BL/6 mouse background for 8 generations. The type I IFN-inducible $\mathrm{M} x$-Cre $\operatorname{Tg}$ C57BL/6 mice (C57BL/6-TgN Mx-Cre mice) were purchased from The Jackson Laboratory. The $M x$-Cre Tg C57BL/6 mice were bred with Foxm $1^{f / f l}$ C57BL/ 6 mice, and the offspring were screened for Mx-Cre Foxm $1^{f / /+}$ mice. These mice were then backcrossed with Foxm $1^{f / f l} \mathrm{C} 57 \mathrm{BL} / 6$ mice to generate $M x$-Cre Foxm $1^{f / f l} \mathrm{C} 57 \mathrm{BL} / 6$ mice. $M x$-Cre Foxm $1^{\text {ll/fl}} \mathrm{C} 57 \mathrm{BL} / 6$ mice were bred with Foxm $1^{l / / f l} \mathrm{C} 57 \mathrm{BL} / 6$ mice to generate a sufficient number of mice for the liver tumor experiments. Charles J. Sherr (St. Jude Children's Research Hospital, Memphis, Tennessee, USA) provided the Arf/- C57BL/6 mice (69). The Arf/- C57BL/6 mice were backcrossed with the Rosa26-FoxM1b FVBN Tg mice, which ubiquitously express the human FoxM1b cDNA (34), to generate Arf/- Rosa26-FoxM1b Tg mice.

At 14 days after birth, each mouse in the litter received a single, i.p. injection of the tumor initiator DEN ( $5 \mu \mathrm{g} / \mathrm{g}$ body weight; catalog N0756; Sigma-Aldrich) to induce liver tumors (8). Two weeks later, male mice were given water containing $0.025 \% \mathrm{~PB}$ tumor promoter for the duration of the experiment (8). At 30 weeks of DEN/PB exposure (which leads to HCC formation), we subjected $M x$-Cre Foxm $1^{f / f l}$ mice to 3 consecutive i.p. injec- 


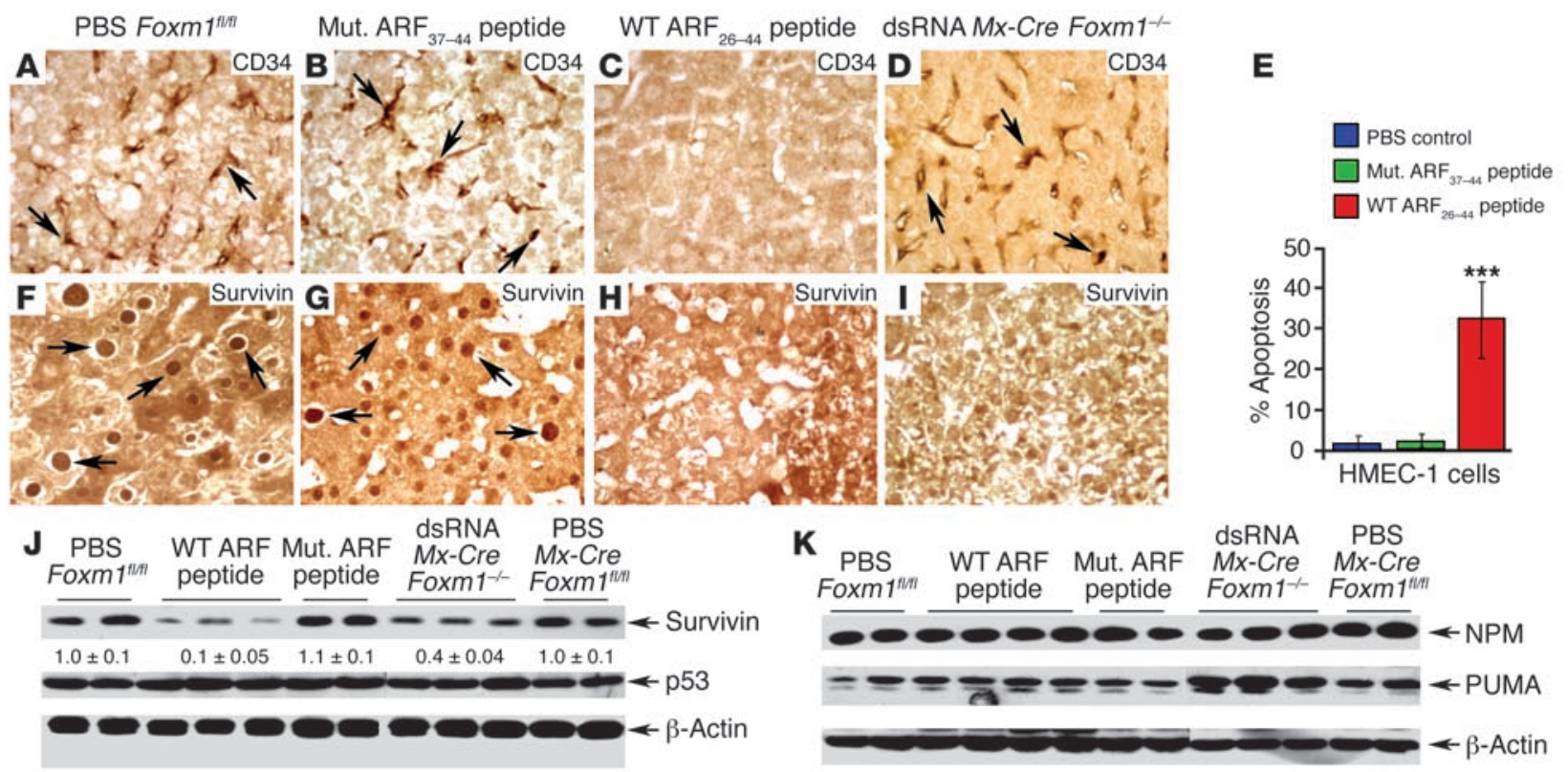

\section{Figure 8}

WT ARF $_{26-44}$ peptide reduces angiogenesis and survivin expression in mouse HCC. The CD34 protein is a marker for newly formed sinusoid-like capillaries in HCC regions (39-41), whereas survivin is critical in preventing apoptosis of tumor cells (45-48). Antibodies specific to either CD34 or survivin were used to immunostain $\mathrm{HCC}$ tumor sections from mice treated with mutant $\mathrm{ARF}_{37-44}$ peptide, WT ARF $26-44$ peptide, or PBS or from

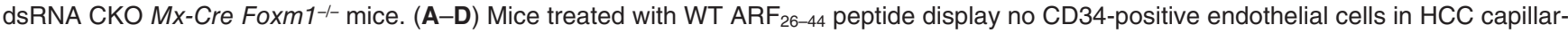
ies, whereas CD34 staining (indicated by arrows) was abundant in endothelial cells of control mouse HCCs. (E) WT ARF $26-44$ peptide induces

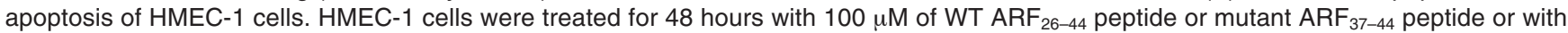
PBS and then assayed for apoptosis as described in Methods. Shown graphically is the percent apoptosis of HMEC-1 cells in response to ARF peptide treatment. (F-I) Reduced survivin expression in $\mathrm{WT} \mathrm{ARF}_{26-44}$ peptide-treated and Foxm1-l- liver tumors. Arrows indicate nuclear staining for survivin protein. (J) Western blot analysis reveals significant decrease in survivin protein expression in WT ARF $26-44$ peptide-treated mouse tumors. (K) No decrease in expression of NPM protein or p53-regulated proapoptotic PUMA protein is found in WT ARF $26-44$ peptide-treated mouse tumors. A slight increase in hepatic tumor levels of PUMA was found in mice treated with dsRNA. Magnification, $\times 400$.

tions (separated by 1 day) of $250 \mu \mathrm{g}$ of synthetic sRNA polyinosinic-polycytidylic acid [poly(I-C); Sigma-Aldrich] (36) to induce expression of the $M x$-Cre transgene and cause deletion of the Foxm $1^{f / f l}$ allele in preexisting liver tumors. We continued PB administration in the drinking water for an additional 10 weeks to allow tumor growth. Livers from mice sacrificed by $\mathrm{CO}_{2}$ asphyxiation were dissected and paraffin embedded for histological staining or immunostaining and for isolation of protein extracts as described previously (8). All protocols used in this study were approved by the animal protocol committee at the University of Illinois at Chicago.

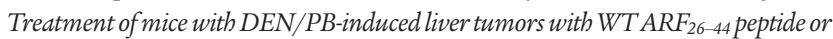
mutant ARF $37-44$ peptide. Genemed Synthesis Inc. synthesized the $\mathrm{WT} \mathrm{ARF}_{26-44}$ peptide (rrrrrrrrrKFVRSRRPRTASCALAFVN) or mutant $\mathrm{ARF}_{37-44}$ peptide (rrrrrrrrrSCALAFVN), both of which contain $9 \mathrm{~N}$-terminal D-Arg $(\mathrm{r})$ residues $(32,33)$ and which are TMR fluorescently tagged (red) at the $\mathrm{N}$-terminus. We chose to i.p. inject mice with this cell-penetrating $\mathrm{WT} \mathrm{ARF}_{26-44}$ peptide to efficiently deliver this peptide to the liver in vivo. In order to determine the effective concentration of dose of the ARF peptide for efficient liver delivery, mice were subjected to i.p. injection of $0.1,1,5$, or $10 \mathrm{mg} / \mathrm{kg}$ body weight of TMR fluorescently tagged WT $\mathrm{ARF}_{26-44}$ peptide and were sacrificed 24 hours later, after which their livers were dissected, formalin fixed, and paraffin embedded as described previously (25). Liver sections were treated with xylene to remove paraffin wax and then examined by fluorescence microscopy for red peptide fluorescence. This dose-response curve determined that i.p. injection of either equal to or greater than $5 \mathrm{mg} / \mathrm{kg}$ body weight of TMR fluorescently tagged WT $\mathrm{ARF}_{26-44}$ peptide was detectable in cytoplasm and nucleolus of hepatocytes and in hepatic mesenchymal cells at 24 hours after injection. Based on these studies, hepatic tumors were induced in Foxm $1^{f / / f l}$ mice by 32 weeks of DEN/PB exposure, and then they were subjected to daily i.p. injections of $5 \mathrm{mg} / \mathrm{kg}$ body weight of the $\mathrm{WT} \mathrm{ARF}_{26-44}$ peptide or mutant $\mathrm{ARF}_{37-44}$ peptide for 4 weeks and with $\mathrm{WT}_{\mathrm{ARF}} \mathrm{A6}_{24}$ peptide for 8 weeks. After 33 weeks of DEN/PB treatment, Arf/-Rosa26-FoxM1b Tg mice were subjected to daily i.p. injections of $5 \mathrm{mg} / \mathrm{kg}$ body weight of the $\mathrm{WT} \mathrm{ARF}_{26-44}$ peptide or mutant $\mathrm{ARF}_{37-44}$ peptide for 4 weeks. Liver tumor-bearing mice were also administered sterile PBS as controls.

BrdU labeling, immunohistochemical staining, and TUNEL apoptosis assay. To monitor hepatic cellular proliferation, PB was removed 4 days prior to the completion of the experiment, and mice were placed on drinking water with $1 \mathrm{mg} / \mathrm{ml}$ of $\mathrm{BrdU}$ for 4 days before they were sacrificed $(8,37)$. Hepatic tumor cell DNA replication in liver sections was determined by immunohistochemical detection of BrdU incorporation as described previously (8). We used an affinity-purified rabbit polyclonal antibody specific to FoxM1b protein (1:500 dilution), which was generated against amino acids $365-748$ of the human FoxM1b protein as described previously (26). We also used the following antibodies specific to the mouse anti-BrdU (Bu20a, 1:100; Dako), rabbit anti-cleaved caspase-3 (5A1, 1:100; Cell Signaling Technology), rabbit anti-survivin (1:250; Novus Biologicals), mouse anti-Kip1/p27 (1:100; BD Biosciences), and rat anti-CD34 (RAM34, 1:100; BD Biosciences) for immunohistochemical detection of 5 - $\mu \mathrm{m}$ liver sections using methods described previously $(8,23,25,29)$. To measure apoptosis in mouse livers, we used the TUNEL assay on liver sections using the ApopTag Fluorescein In Situ Apoptosis Detection Kit from Intergen according to the manufacturer's recommendations. We calculated the mean number $( \pm \mathrm{SD})$ of TUNEL- or 

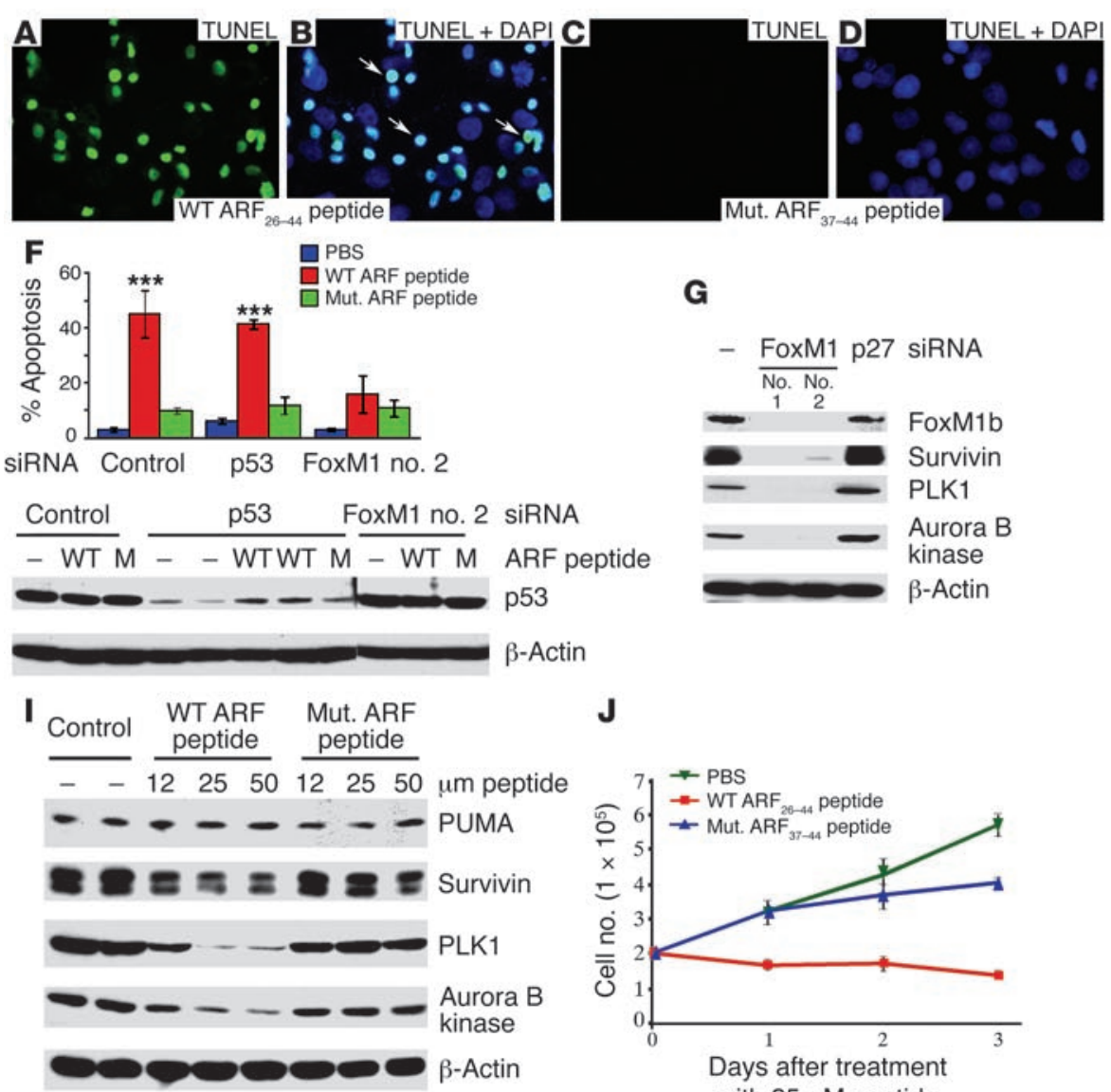

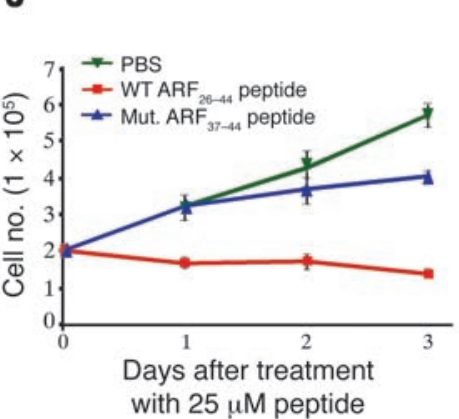

G



with $25 \mu \mathrm{M}$ peptide
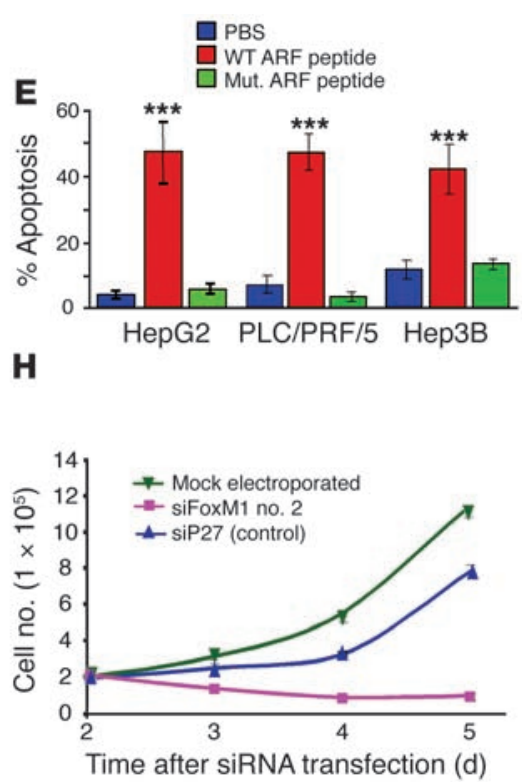

$\mathbf{K}$



Figure 9

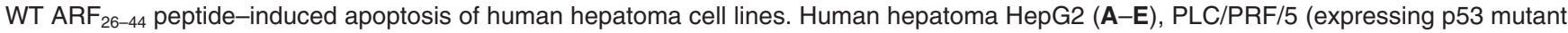
protein), or Hep3B (p53-deficient) cells were treated for 24 hours with $25 \mu \mathrm{M}$ of WT ARF $\mathrm{AR}_{26-44}$ or mutant ARF $37-44$ peptide; they were then analyzed for apoptosis by TUNEL assay, and percent apoptosis $( \pm \mathrm{SD})$ was calculated $\left(\mathbf{E} ;{ }^{* *} P \leq 0.001\right)$. Merged DAPI and TUNEL staining $(\mathbf{A}$ and $\mathbf{C})$ images show TUNEL-positive nuclei of HepG2 cells (white arrows; B and D). (F) Graphic representation of WT ARF $26-44$ peptide-treated HepG2 cells showing that apoptosis is induced in p53-depleted cells but not in FoxM1-deficient cells. Western blot analysis is presented below the graph, showing effective downregulation of p53 protein levels following p53 siRNA electroporation and that treatment with WT ARF $26-44$ (WT) or mutant $\mathrm{ARF}_{37-44}$ peptide (M) does not alter p53 protein levels. (G and I) At 48 hours after electroporation with siFoxM1 no. 2 or p27 siRNA duplexes $(\mathbf{G})$, or treatment with WT or mutant ARF peptide (I), HepG2 cells were analyzed for protein expression of survivin, PLK1, and aurora B kinase by Western blot analysis. We also determined a growth curve of HepG2 cells at the indicated days following siRNA transfection (H) or at the indicated days after ARF peptide treatment $(\mathbf{J})$ as described in Methods. $(\mathbf{K})$ Model summarizing findings in this article with WT ARF $26-44$ peptide. Magnification, $\times 400$.

DAPI-positive hepatocyte nuclei per 1,000 cells or $\times 200$ field by counting the number of positive hepatocyte nuclei using 5 different $\times 200$ fields of liver tumor sections from male mice at the indicated times of $\mathrm{DEN} / \mathrm{PB}$ exposure. We used 5 liver tumor sections from 3 mice to calculate the mean number of BrdU-positive cells $( \pm \mathrm{SD})$ per square millimeter liver tumor. To calculate the area or size of liver tumors, we used micrographs of H\&E-stained liver tumor sections taken by an Axioplan 2 microscope (Zeiss) and the AxioVision program (version 4.3; Zeiss).

Western blot analysis. For Western blot analysis, $75 \mu \mathrm{g}$ of total protein extracts prepared from liver were separated on SDS-PAGE and transferred to a PVDF membrane (Bio-Rad) as described previously (25). The following commercially available antibodies and dilutions were used for Western blotting: mouse anti-Plk-1 (F-8, 1:500; Santa Cruz Biotechnology Inc.), mouse anti-p53 (FL-393, 1:500; Santa Cruz Biotechnology Inc.), mouse anti-MDM2 (SMP14, 1:500; Santa Cruz Biotechnology Inc.), mouse anti- $\beta$-actin (AC-15,
1:5,000; Sigma-Aldrich), mouse anti-aurora B kinase/AIM-1 (1:1,000; BD Biosciences), rabbit anti-survivin (1:2,000; Novus Biologicals), mouse antiPUMA (1:1,000; Cell Signaling Technology), and mouse anti-NPM/B23 $(1: 15,000 ; Z y m e d)$. The primary antibody signals were amplified by HRPconjugated secondary antibodies (Bio-Rad) and detected with Enhanced Chemiluminescence Plus (ECL Plus; Amersham Biosciences). Western blot analysis was performed with liver extracts from 2-4 mice per indicated time point following DEN/PB treatment, and signal intensities were normalized to $\beta$-actin signals. Quantitation of expression levels was determined with tiff files from scanned films using the BioMax 1D software program (Kodak).

Treatment of doxycycline-inducible U2OS C3 cells with WT ARF $26-44$ peptide or mutant $A R F_{37-44}$ peptide. We previously reported on the generation and growth of an osteosarcoma U2OS clone C3 cell line (U2OS C3 cells) that allowed doxycycline-inducible (Dox-inducible) expression of the GFP-FoxM1b fusion protein (24). For induced expression of the GFP-FoxM1b fusion 
protein, we added $1 \mu \mathrm{g} / \mathrm{ml}$ of Dox (Sigma-Aldrich). In order to determine the FoxM1b localization in U2OS C3 cells, they were treated with $12 \mu \mathrm{M}$ of the TMR fluorescently tagged WT $\mathrm{ARF}_{26-44}$ or mutant $\mathrm{ARF}_{37-44}$ peptide for 24 hours. U2OS C3 cells were fixed with $10 \%$ buffered formalin (Fisher Scientific) for 20 minutes at room temperature and rinsed with PBS, and cover glasses were mounted with VECTASHIELD Mounting Medium with DAPI (catalog H-1200; Vector Laboratories). Immunofluorescence was detected using an Axioplan 2 microscope.

Treatment of human hepatoma cell lines with WT ARF $F_{26-44}$ or mutant $A R F_{37-44}$ peptide and siRNA transfection. HepG2 cells were plated on 100-mm plates in Ham's F-12 medium supplemented with $10 \%$ FCS, $100 \mathrm{IU} / \mathrm{ml}$ penicillin, $100 \mu \mathrm{g} / \mathrm{ml}$ streptomycin, $2 \mathrm{mM}$ L-glutamine, and $0.5 \mathrm{U}$ Humulin (insulin; Lilly). HepG2 cells were treated with $12 \mu \mathrm{M}, 25 \mu \mathrm{M}$, or $50 \mu \mathrm{M}$ of $\mathrm{WT} \mathrm{ARF}_{26-44}$ peptide or mutant $\mathrm{ARF}_{37-44}$ peptide for 24 hours and used to prepare whole-cell protein extracts using the NP40 lysis buffer as described previously (26), and Western blot analysis was performed as described above. HepG2 cells were treated with $25 \mu \mathrm{M}$ of WT $\mathrm{ARF}_{26-44}$ peptide or mutant $\mathrm{ARF}_{37-44}$ peptide for 24 hours, and HepG2 cell apoptosis was determined by TUNEL assay using the ApopTag Fluorescein In Situ Apoptosis Detection Kit from Intergen according to the manufacturer's recommendations. We calculated the percent apoptosis of HepG2 cells $( \pm \mathrm{SD})$ by counting the number of TUNEL-positive cells (green fluorescence) per 1,000 nuclei as visualized by DAPI (blue fluorescence) counterstaining.

Human hepatoma PLC/PRF/5 and Hep3B cell lines (ATCC) were grown as a monolayer on 100-mm plates in DMEM supplemented with $10 \%$ FCS, $100 \mathrm{IU} / \mathrm{ml}$ penicillin, $100 \mu \mathrm{g} / \mathrm{ml}$ streptomycin, and $2 \mathrm{mM}$ L-glutamine. Human hepatoma PLC/PRF/5 and Hep3B cells were treated with $25 \mu \mathrm{M}$ of WT ARF $26-44$ peptide or mutant $\mathrm{ARF}_{37-44}$ peptide for 24 hours, and cells undergoing apoptosis were determined by TUNEL assay as described above.

Transfection of human cells with FoxM1 siRNA duplexes (Dharmacon RNA Technologies), named siFoxM1 no. 1 (CAACAGGAGUCUAAUCAAG) and siFoxM1 no. 2 (GGACCACUUUCCCUACUUU), efficiently depleted FoxM1 levels as described previously (26). We also previously used the human p27 $^{\text {Kip } 1}$ siRNA duplex (GUACGAGUGGCAAGAGGUGUU) as a control siRNA, which did not influence expression of the FoxM1 gene (26). Human p53 siRNA duplex was purchased from Cell Signaling Technology Inc. These siRNA duplexes were transfected into HepG2 cells using the Nucleofector II apparatus and buffers recommended by the manufacturer (Amaxa Biosystems). Forty-eight hours after electroporation to allow siRNA silencing, HepG2 cells were treated with $25 \mu \mathrm{M}$ of WT $\mathrm{ARF}_{26-44}$ peptide or mutant $\mathrm{ARF}_{37-44}$ peptide for 24 hours and then examined for apoptosis by TUNEL assay. HepG2 cells were harvested at 72 hours after FoxM1 siRNA or p27 siRNA transfection to prepare protein extracts for Western blot analysis to examine expression of PUMA, survivin, PLK1, and aurora B kinase proteins as described above. HepG2 cells were harvested at 48 hours after p53 siRNA transfection or at 72 hours after p 53 siRNA transfection and examined for apoptosis as described above.
Treatment of HMEC-1 cells with WT ARF $26-44$ or mutant ARF $37-44$ peptide. HMEC-1 cells (ATCC) were grown as monolayer cultures on $100-\mathrm{mm}$ plates in MCDB 131 medium supplemented with 15\% FCS, $100 \mathrm{IU} / \mathrm{ml}$ penicillin, $100 \mu \mathrm{g} / \mathrm{ml}$ streptomycin, $10 \mathrm{ng} / \mathrm{ml} \mathrm{EGF}$ (Sigma-Aldrich), and $1 \mu \mathrm{g} / \mathrm{ml}$ hydrocortisone (Sigma-Aldrich). HMEC-1 cells were treated for 48 hours with $100 \mu \mathrm{M}$ of $\mathrm{WT} \mathrm{ARF}_{26-44}$ peptide or mutant $\mathrm{ARF}_{37-44}$ peptide and then examined for apoptosis as described above.

Growth curve of HepG2 cells electroporated with FoxM1 or p27Kip1 siRNA or treated with WT or ARF peptide. HepG2 cells were electroporated with $100 \mathrm{nM}$ of FoxM1 (FoxM1 no. 2) or p27 $7^{\text {Kip } 1 ~(s i P 27) ~ s i R N A ~ d u p l e x e s ~(26) ~ u s i n g ~}$ the Nucleofector II apparatus (Amaxa Biosystems) and eletroporation buffers recommended by the manufacturer for HepG2 cells. HepG2 cells were replated for 2 days to allow siRNA silencing of FoxM1 or p27 $7^{\text {Kip } 1}$ levels, and then $2 \times 10^{5} \mathrm{HepG} 2$ cells were plated in triplicate, and viable HepG2 cells were counted at 2, 3, 4, or 5 days following electroporation. Mock-electroporated cells were used as controls. We also plated $2 \times 10^{5}$ HepG2 cells in triplicate, and viable HepG2 cells were counted at 1, 2,


mutant $\mathrm{ARF}_{37-44}$ peptide. After 2 days in culture, media was replaced with $50 \mu \mathrm{M}$ of $\mathrm{WT} \mathrm{ARF}_{26-44}$ peptide or mutant $\mathrm{ARF}_{37-44}$ peptide. PBS-treated cells were used as controls.

Statistics. We used the Microsoft Excel program to calculate SD and statistically significant differences between samples using the 2-tailed Student's $t$ test. The asterisks in each graph indicate statistically significant changes with $P$ values calculated by Student's $t$ test: ${ }^{*} P<0.05,{ }^{* *} P \leq 0.01$, and ${ }^{*}{ }^{*} P \leq 0.001$. $P$ values less than 0.05 were considered statistically significant.

\section{Acknowledgments}

This work was supported by US Public Health Service Grants R01 DK 54687 from the NIDDK, R01 CA124488 from the National Cancer Institute, and R01 AG 21842 from the National Institute on Aging (to R.H. Costa). We thank H. Yoder, W. Wang, and B. Shin for excellent technical assistance and B. Merrill and P. Raychaudhuri for helpful discussions and critical review of this paper.

Received for publication November 29, 2005, and accepted in revised form October 10, 2006.

Address correspondence to: Galina A. Gusarova, Department of Biochemistry and Molecular Genetics (M/C 669), University of Illinois at Chicago, College of Medicine, 900 S. Ashland Ave., MBRB Rm. 2268, Chicago, Illinois 60607-7170, USA. Phone: (312) 996-6994; Fax: (312) 355-4010; E-mail: gusarova@uic.edu.

While the revised manuscript was in preparation, Robert $\mathrm{H}$. Costa died in his fight against pancreatic cancer. The authors dedicate this work to his memory.
1. Bruix, J., Boix, L., Sala, M., and Llovet, J.M. 2004 Focus on hepatocellular carcinoma. Cancer Cell. 5:215-219.

2. Massague, J. 2004. G1 cell-cycle control and cancer. Nature. 432:298-306.

3. Franke, T.F., Hornik, C.P., Segev, L., Shostak, G.A., and Sugimoto, C. 2003. PI3K/Akt and apoptosis: size matters. Oncogene. 22:8983-8998.

4. Sherr, C.J. 2004. Principles of tumor suppression. Cell. 116:235-246.

5. Calvisi, D.F., and Thorgeirsson, S.S. 2005. Molecular mechanisms of hepatocarcinogenesis in transgenic mouse models of liver cancer. Toxicol. Pathol. 33:181-184.

6. Calvisi, D.F., et al. 2005. Activation of the canonical Wnt/beta-catenin pathway confers growth advan- tages in c-Myc/E2F1 transgenic mouse model of liver cancer. J. Hepatol. 42:842-849.

7. Sandgren, E.P., et al. 1993. Transforming growth factor $\alpha$ dramatically enhances oncogene-induced carcinogenesis in transgenic mouse pancreas and liver. Mol. Cell. Biol. 13:320-330.

8. Kalinichenko, V.V., et al. 2004. Forkhead box m1b transcription factor is essential for development of hepatocellular carcinomas and is negatively regulated by the p19ARF tumor suppressor. Genes Dev. 18:830-850.

9. Lee, J.S., et al. 2004. Application of comparative functional genomics to identify best-fit mouse models to study human cancer. Nat. Genet. 36:1306-1311.

10. Lowe, S.W., and Sherr, C.J. 2003. Tumor suppression by Ink4a-Arf: progress and puzzles. Curr. Opin.
Genet. Dev. 13:77-83.

11. Datta, A., Nag, A., and Raychaudhuri, P. 2002. Differential regulation of E2F1, DP1, and the E2F1/ DP1 complex by ARF. Mol. Cell. Biol. 22:8398-8408.

12. Datta, A., et al. 2004. Myc-ARF (alternate reading frame) interaction inhibits the functions of Myc. J. Biol. Chem. 279:36698-36707.

13. Martelli, F., et al. 2001. p19ARF targets certain E2F species for degradation. Proc. Natl. Acad. Sci. U. S. A. 98:4455-4460.

14. Qi, Y., et al. 2004. p19(ARF) directly and differentially controls the functions of c-Myc independently of p53. Nature. 431:712-717.

15. Carlsson, P., and Mahlapuu, M. 2002. Forkhead transcription factors: key players in development and metabolism. Dev. Biol. 250:1-23. 
16. Kaestner, K.H., Knochel, W., and Martinez, D.E. 2000. Unified nomenclature for the winged helix/forkhead transcription factors. Genes Dev. 14:142-146.

17. Clark, K.L., Halay, E.D., Lai, E., and Burley, S.K. 1993. Co-crystal structure of the HNF-3/fork head DNA-recognition motif resembles histone H5. Nature. 364:412-420.

18. Marsden, I., Jin, C., and Liao, X. 1998. Structural changes in the region directly adjacent to the DNAbinding helix highlight a possible mechanism to explain the observed changes in the sequence-specific binding of winged helix proteins. J. Mol. Biol. 278:293-299.

19. Korver, W., Roose, J., and Clevers, H. 1997. The winged-helix transcription factor Trident is expressed in cycling cells. Nucleic Acids Res. 25:1715-1719.

20. Luscher-Firzlaff, J.M., et al. 1999. Interaction of the fork head domain transcription factor MPP2 with the human papilloma virus 16 E7 protein: enhancement of transformation and transactivation. Oncogene. 18:5620-5630.

21. Yao, K.M., Sha, M., Lu, Z., and Wong, G.G. 1997. Molecular analysis of a novel winged helix protein, WIN. Expression pattern, DNA binding property, and alternative splicing within the DNA binding domain. J. Biol. Chem. 272:19827-19836.

22. Ye, H., et al. 1997. Hepatocyte nuclear factor $3 /$ fork head homolog 11 is expressed in proliferating epithelial and mesenchymal cells of embryonic and adult tissues. Mol. Cell. Biol. 17:1626-1641.

23. Ye, H., Holterman, A., Yoo, K.W., Franks, R.R., and Costa, R.H. 1999. Premature expression of the winged helix transcription factor $\mathrm{HFH}-11 \mathrm{~B}$ in regenerating mouse liver accelerates hepatocyte entry into S-phase. Mol. Cell. Biol. 19:8570-8580.

24. Major, M.L., Lepe, R., and Costa, R.H. 2004. Forkhead box M1B (FoxM1B) transcriptional activity requires binding of $\mathrm{Cdk} /$ Cyclin complexes for phosphorylation-dependent recruitment of p300 CBP co-activators. Mol. Cell. Biol. 24:2649-2661.

25. Wang, X., Kiyokawa, H., Dennewitz, M.B., and Costa, R.H. 2002. The Forkhead box m1b transcription factor is essential for hepatocyte DNA replication and mitosis during mouse liver regeneration. Proc. Natl. Acad. Sci. U. S. A. 99:16881-16886.

26. Wang, I.-C., et al. 2005. Forkhead box M1 regulates the transcriptional network of genes essential for mitotic progression and genes encoding the SCF (Skp2-Cks1) ubiquitin ligase. Mol. Cell. Biol. 25:10875-10894.

27. Pagano, M. 2004. Control of DNA synthesis and mitosis by the Skp2-p27-Cdk1/2 axis. Mol. Cell. 14:414-416

28. Wang, X., et al. 2001. Increased levels of Forkhead box M1B transcription factor in transgenic mouse hepatocytes prevents age-related proliferation defects in regenerating liver. Proc. Natl. Acad. Sci. U. S. A. 98:11468-11473.

29. Krupczak-Hollis, K., et al. 2004. The mouse Forkhead box $\mathrm{m} 1$ transcription factor is essential for hepatoblast mitosis and development of intrahepatic bile ducts and vessels during liver morphogenesis. Dev. Biol. 276:74-88.

30. Laoukili, J., et al. 2005. FoxM1 is required for execution of the mitotic programme and chromosome stability. Nat. Cell Biol. 7:126-136.

31. Costa, R.H., Kalinichenko, V.V., Major, M.L., and Raychaudhuri, P. 2005. New and unexpected: forkhead meets ARF. Curr. Opin. Genet. Dev. 15:42-48.

32. Fuchs, S.M., and Raines, R.T. 2004. Pathway for polyarginine entry into mammalian cells. Biochemistry. 43:2438-2444.
33. Wender, P.A., et al. 2000. The design, synthesis, and evaluation of molecules that enable or enhance cellular uptake: peptoid molecular transporters. Proc. Natl. Acad. Sci. U. S. A. 97:13003-13008

34. Kalinichenko, V.V., et al. 2003. Ubiquitous expression of the forkhead box M1B transgene accelerates proliferation of distinct pulmonary cell-types following lung injury. J. Biol. Chem. 278:37888-37894.

35. Kalin, T.V., et al. 2006. Increased levels of the FoxM1 transcription factor accelerate development and progression of prostate carcinomas in both TRAMP and LADY transgenic mice. Cancer Res. 66:1712-1720.

36. Kuhn, R., Schwenk, F., Aguet, M., and Rajewsky, K. 1995. Inducible gene targeting in mice. Science. 269:1427-1429.

37. Ledda-Columbano, G.M., et al. 2002. Loss of cyclin D1 does not inhibit the proliferative response of mouse liver to mitogenic stimuli. Hepatology. 36:1098-1105

38. Rizos, H., Darmanian, A.P., Mann, G.J., and Kefford, R.F. 2000. Two arginine rich domains in the p14ARF tumour suppressor mediate nucleolar localization. Oncogene. 19:2978-2985.

39. Cui, S., et al. 1996. Enhanced CD34 expression of sinusoid-like vascular endothelial cells in hepatocellular carcinoma. Pathol. Int. 46:751-756.

40. Ohmori, S., et al. 2001. High expression of CD34positive sinusoidal endothelial cells is a risk factor for hepatocellular carcinoma in patients with $\mathrm{HCV}$-associated chronic liver diseases. Hum. Pathol. 32:1363-1370

41. Tanigawa, N., Lu, C., Mitsui, T., and Miura, S. 1997. Quantitation of sinusoid-like vessels in hepatocellular carcinoma: its clinical and prognostic significance. Hepatology. 26:1216-1223.

42. Sampath, S.C., et al. 2004. The chromosomal passenger complex is required for chromatin-induced microtubule stabilization and spindle assembly. Cell. 118:187-202.

43. Temme, A., et al. 2003. Localization, dynamics, and function of survivin revealed by expression of functional survivinDsRed fusion proteins in the living cell. Mol. Biol. Cell. 14:78-92.

44. Wheatley, S.P., Henzing, A.J., Dodson, H., Khaled, W., and Earnshaw, W.C. 2004. Aurora-B phosphorylation in vitro identifies a residue of survivin that is essential for its localization and binding to inner centromere protein (INCENP) in vivo. J. Biol. Chem. 279:5655-5660.

45. Altieri, D.C. 2003. Survivin, versatile modulation of cell division and apoptosis in cancer. Oncogene. 22:8581-8589.

46. Ikeguchi, M., Ueda, T., Sakatani, T., Hirooka, Y., and Kaibara, N. 2002. Expression of survivin messenger RNA correlates with poor prognosis in patients with hepatocellular carcinoma. Diagn. Mol. Pathol. 11:33-40.

47. Kawasaki, H., et al. 2001. Expression of survivin correlates with apoptosis, proliferation, and angiogenesis during human colorectal tumorigenesis. Cancer. 91:2026-2032.

48. Sarela, A.I., Macadam, R.C., Farmery, S.M., Markham, A.F., and Guillou, P.J. 2000. Expression of the antiapoptosis gene, survivin, predicts death from recurrent colorectal carcinoma. Gut. 46:645-650.

49. Korgaonkar, C., et al. 2005. Nucleophosmin (B23) targets ARF to nucleoli and inhibits its function. Mol. Cell. Biol. 25:1258-1271.

50. Brady, S.N., Yu, Y., Maggi, L.B., Jr. and Weber, J.D. 2004. ARF impedes NPM/B23 shuttling in an $\mathrm{Mdm} 2$-sensitive tumor suppressor pathway. Mol.
Cell. Biol. 24:9327-9338.

51. Bertwistle, D., Sugimoto, M., and Sherr, C.J. 2004. Physical and functional interactions of the Arf tumor suppressor protein with nucleophosmin/B23. Mol. Cell. Biol. 24:985-996.

52. Chipuk, J.E., Bouchier-Hayes, L., Kuwana, T., Newmeyer, D.D., and Green, D.R. 2005. PUMA couples the nuclear and cytoplasmic proapoptotic function of p53. Science. 309:1732-1735.

53. Jeffers, J.R., et al. 2003. Puma is an essential mediator of p53-dependent and -independent apoptotic pathways. Cancer Cell. 4:321-328.

54. Nakano, K., and Vousden, K.H. 2001. PUMA, a novel proapoptotic gene, is induced by $553 . \mathrm{Mol}$. Cell. 7:683-694.

55. Villunger, A., et al. 2003. p53- and drug-induced apoptotic responses mediated by $\mathrm{BH} 3$-only proteins puma and noxa. Science. 302:1036-1038.

56. Fan, Y., Zheng, S., Xu, Z.F., and Ding, J.Y. 2005. Apoptosis induction with polo-like kinase-1 antisense phosphorothioate oligodeoxynucleotide of colon cancer cell line SW480. World J. Gastroenterol. 11:4596-4599.

57. Guan, R., et al. 2005. Small interfering RNA-mediated Polo-like kinase 1 depletion preferentially reduces the survival of p53-defective, oncogenic transformed cells and inhibits tumor growth in animals. Cancer Res. 65:2698-2704.

58. Gumireddy, K., et al. 2005. ON01910, a non-ATPcompetitive small molecule inhibitor of Plk1, is a potent anticancer agent. Cancer Cell. 7:275-286.

59. Harrington, E.A., et al. 2004. VX-680, a potent and selective small-molecule inhibitor of the Aurora kinases, suppresses tumor growth in vivo. Nat. Med. 10:262-267.

60. Liu, X., and Erikson, R.L. 2003. Polo-like kinase (Plk)1 depletion induces apoptosis in cancer cells. Proc. Natl. Acad. Sci. U. S. A. 100:5789-5794.

61. Reagan-Shaw, S., and Ahmad, N. 2005. Silencing of polo-like kinase (Plk) 1 via siRNA causes induction of apoptosis and impairment of mitosis machinery in human prostate cancer cells: implications for the treatment of prostate cancer. FASEB J. 19:611-613.

62. Spankuch-Schmitt, B., Bereiter-Hahn, J., Kaufmann, M., and Strebhardt, K. 2002. Effect of RNA silencing of polo-like kinase-1 (PLK1) on apoptosis and spindle formation in human cancer cells. J. Natl. Cancer Inst. 94:1863-1877.

63. Wonsey, D.R., and Follettie, M.T. 2005. Loss of the forkhead transcription factor FoxM1 causes centrosome amplification and mitotic catastrophe. Cancer Res. 65:5181-5189.

64. Santoni-Rugiu, E., Jensen, M.R., Factor, V.M., and Thorgeirsson, S.S. 1999. Acceleration of c-mycinduced hepatocarcinogenesis by Co-expression of transforming growth factor (TGF)-alpha in transgenic mice is associated with TGF-beta1 signaling disruption. Am. J. Pathol. 154:1693-1700.

65. Weber, J.D., et al. 2000. Cooperative signals governing ARF-mdm 2 interaction and nucleolar localization of the complex. Mol. Cell. Biol. 20:2517-2528.

66. Datta, A., et al. 2005. ARF directly binds DP1: interaction with DP1 coincides with the G1 arrest function of ARF. Mol. Cell. Biol. 25:8024-8036.

67. Reef, S., et al. 2006. A short mitochondrial form of p19ARF induces autophagy and caspase-independent cell death. Mol. Cell. 22:463-475.

68. Zhao, R., and Duncan, S.A. 2005. Embryonic development of the liver. Hepatology. 41:956-967.

69. Kamijo, T., Bodner, S., van de Kamp, E., Randle, D.H., and Sherr, C.J. 1999. Tumor spectrum in ARF-deficient mice. Cancer Res. 59:2217-2222. 